\title{
Aerogel-based thermal superinsulation: an overview
}

\author{
Matthias Koebel $\cdot$ Arnaud Rigacci $\cdot$ \\ Patrick Achard
}

Received: 7 March 2012/ Accepted: 27 April 2012/Published online: 15 May 2012

(C) Springer Science+Business Media, LLC 2012

\begin{abstract}
This review is focused on describing the intimate link which exists between aerogels and thermal superinsulation. For long, this applied field has been considered as the most promising potential market for these nanomaterials. Today, there are several indicators suggesting that this old vision is likely to become reality in the near future. Based on recent developments in the field, we are confident that aerogels still offer the greatest potential for non-evacuated superinsulation systems and consequently must be considered as an amazing opportunity for sustainable development. The practical realization of such products however is time-consuming and a significant amount of $R \& D$ activities are still necessary to yield improved aerogelbased insulation products for mass markets.
\end{abstract}

Keywords Aerogel - Composite materials .

Superinsulation - Thermal insulation - Insulation market . Energy efficient buildings - Commercialization · Sol-gel · Thermal conductivity $\cdot$ Structure dependence $\cdot$ Ambient pressure drying $\cdot$ Supercritical $\mathrm{CO}_{2} \cdot$ Hydrophobization

M. Koebel ( $\square)$

Empa, Swiss Federal Laboratories for Materials Science and Technology, Überlandstrasse 129,

8600 Dübendorf, Switzerland

e-mail: matthias.koebel@empa.ch

A. Rigacci · P. Achard

MINES ParisTech, CEP, Centre Energétique et Procédés,

BP 207, 06904 Sophia Antipolis, France

e-mail: arnaud.rigacci@mines-paristech.fr

P. Achard

e-mail: patrick.achard@mines-paristech.fr

\section{Global need for superinsulation solutions}

\subsection{Why superinsulation?}

Ever since the first global oil crisis in the seventies, the scarcity of fossil fuels, which is the number one resource for our chemical industry and energy carrier, has underlined the dependence of modern society on cheap energy and resources [1]. Over short or long term, that very fact is forcing humanity to rethink global energy strategies and consequently take appropriate measures. In addition to a limited supply of carbon based fuels worldwide, the effect of the carbon footprint i.e. the influence of a rising carbon dioxide $\left(\mathrm{CO}_{2}\right)$ concentration in the earth's atmosphere [2] and its effect on the global climate [3, 4], has become indisputably clear: wide media coverage has inseminated public awareness at the turn of the millennium. Pictures displaying the melting polar cap went around the world leaving its spectator in a state of awe: the effects of the humans triumph through stellar advancements in the technological age can no longer be denied. Suddenly it is becoming clear that our precious technology and free market economy is threatening the continuity of our very existence.

Having come to this realization, international political efforts are asking for immediate solutions to the global warming and climate change problems. A goal often cited in this context is the stabilization of the atmospheric $\mathrm{CO}_{2}$ concentration below 500 parts per million [5]. The necessity for action and a rapidly increasing demand for renewable energy sources (sources with no net emission of $\mathrm{CO}_{2}$ ) led to an overestimation of the potential and speed of implementation of such technologies, a statement which describes the current situation quite adequately. Even though absolutely necessary for our advancement and an 
Fig. 1 Appropriate strategies for halting global climate change sorted by time and source. Immediate action and a proper combination of short-, medium- and long-term measures is essential for the future habitability of the earth (From [7], chapter 26)

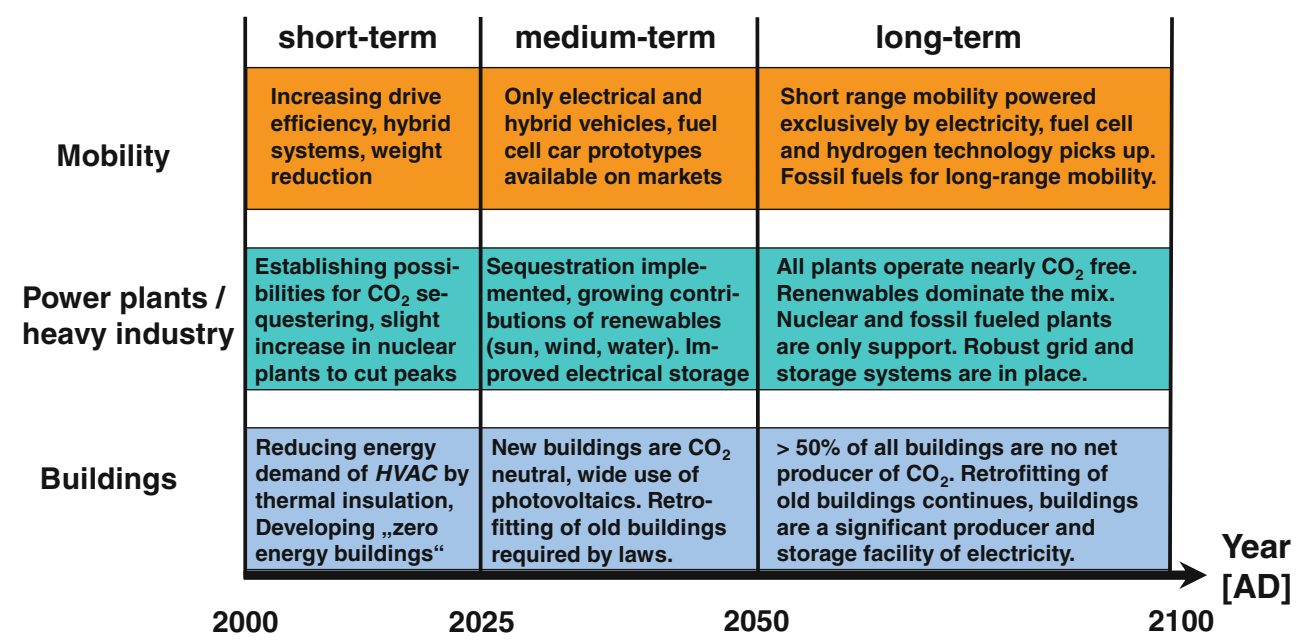

essential investment in our future, the development of alternative energy schemes is an arduous task and will take decades if not centuries to completely replace current technology. Our dependence on oil, gas and coal (>85\% of the world energy demand in 2003) is much deeper than most people feel comfortable to admit. It is therefore completely unrealistic to assume that renewable energies will be able, like certain groups claim, to replace a significant fraction of carbon based energy carriers in the next 10-20 years. The main reasons for an immediate implementation and delayed action are technological difficulties and economic barriers [6]. This realization automatically leads to a limited number of reasonable strategies for a global reduction of $\mathrm{CO}_{2}$ and greenhouse gas emissions. An ideal course of action requires short, medium and longterm strategies to bridge gaps while developing long-term renewable energy supply systems for the blue planet.

Figure 1 illustrates a realistic scenario including necessary steps required to stay on track with the ambitious goal to stabilize the atmospheric $\mathrm{CO}_{2}$ concentration at 500 parts per million by the year 2100 . Those measures are divided into the main $\mathrm{CO}_{2}$ emitters namely mobility (vehicles, ships, planes including transport of goods), power plants/ heavy industry and buildings. Surprisingly to most people, buildings account for approximately $40 \%$ of the global energy consumption, a larger share than that of the entire mobility sector. With it comes a $\mathrm{CO}_{2}$ footprint of a similar magnitude. The buildings sector is marked by another key feature: whereas current technologies used in transportation, power plants and heavy industries are optimized to a large extent, the same is not true for the energy saving potential of buildings [8]. HVAC (heating, ventilation and air conditioning) has the lion's share of a buildings total energy demand, however in many areas of the world (almost everywhere except in central \& northern Europe) the actual thermal insulation standards leave much to be desired. Hence, the vast stock of poorly insulated buildings around the globe adds up to a tremendous short-term potential for reducing $\mathrm{CO}_{2}$ emissions right away, here and now.

\subsection{Buildings as a tremendous market opportunity}

Working out ways to propel the use of renewable energy sources and to render transportation even more efficient are great challenges and will require several decades to be realized commercially. This is partly due to the fact that current transportation systems (automotive, aviation, trains) are already highly optimized, and in order to achieve yet another significant efficiency boost, new technologies need to be developed and upscaled at the commercial level. Obviously this is a rather time-intensive process. However, in order to stay on track with climate change protocols, immediate measures are required to start curtailing the $\mathrm{CO}_{2}$ output now. One of the most promising ways to achieve this is of course a reduction of the energy consumption of buildings HVAC systems. This can be done with minimal effort by putting in place proper thermal insulation. If the climate change is to be taken seriously, society first must demand that improved insulation solutions be put in place. This concerns both new and already existing buildings, even though the savings potential in the case of older structures is considerably larger. The most economical way to achieve a reduction in thermal losses of buildings is to install thicker layers of conventional insulation materials. There is of course an aesthetic disadvantage associated with such a cumbersome facade construction: the insulated object takes up more space, the volume fraction of inhabitable living space decreases. In most cases, cost and insulation performance are the primary parameters for new constructions and retrofitting of buildings. Figure 2 shows a simplified view of the correlation between cost, performance and the market share in the insulation sector. The attribute "space saving" goes 


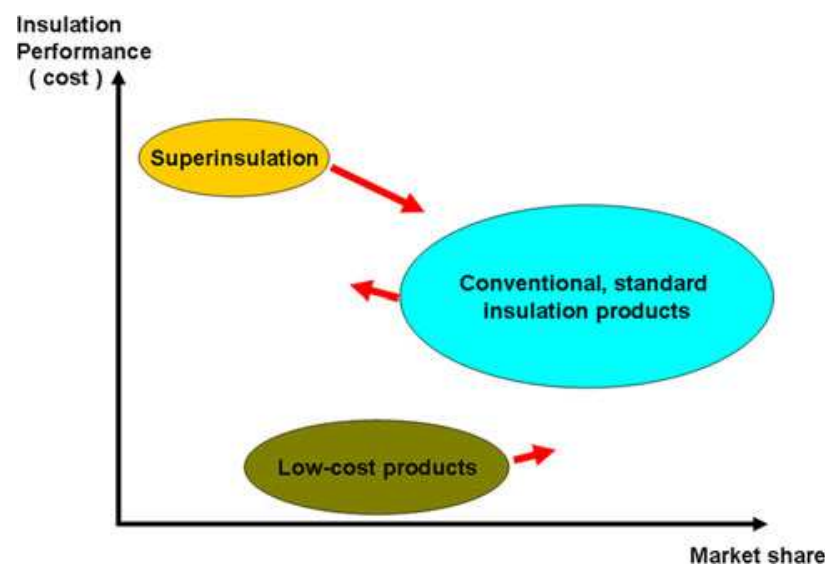

Fig. 2 Market share displayed by cost/performance: high-performance (superinsulation) and low-cost products have smaller market shares. The red arrows symbolize the expected development of each segment in the future (From [7], chapter 26)

hand in hand with cost and insulation performance as criteria for choosing building insulation. The conventional or standard insulation products sector [9] is the most representative of the average building owner's need when shopping for insulation as it offers the best performance per unit cost. Superinsulation offers improved performance but at a significantly higher cost. Low-cost products offer poor performance (and durability) for an extremely low price.

The use of superinsulation is restricted to areas where it can offer a cost advantage due to a space-saving effect, improved service-life (lower servicing/support cost) or advanced product properties (resistance against chemicals, high or low temperature, etc.). In the building sector, space saving is the number one reason for the use of superinsulation. Typical examples include side-on balcony and accessible roof balcony constructions, interior insulation solutions for building retrofit as well as slim façade insulation for the renovation of historical buildings. A number of other niche insulation markets outside of the building sector such as thermal insulation for apparel, aerospace, petrochemical pipelines and pumping fluid media in industry applications as well as low-temperature processes are worth mentioning and will be discussed in more detail later on.

\section{High-performance insulation or superinsulation: concept and examples}

\subsection{Definition and materials classification}

Thus far we have established definitions for markets and applications for superinsulation products. But perhaps the key question has not been addressed this far: How does a material or component classify as a superinsulator? One of the simplest ways to define the two synonyms "superinsulation" or "high-performance insulation" is via the thermal conductivity $\lambda$ (lambda) measured under standard (ambient) conditions. The thermal conductivity is an intrinsic materials property and is defined by the heat flow through a slab of material of area A and thickness d with an effective temperature difference $\Delta \mathrm{T}$ acting on the two surfaces. The units of $\lambda$ are $\left(\mathrm{Wm}^{-1} \mathrm{~K}^{-1}\right)$. Metals are extremely good thermal conductors with $\lambda$ values in the tens to hundreds of $\mathrm{Wm}^{-1} \mathrm{~K}^{-1}$ range. Glass, sand and minerals have typical thermal conductivities in the single digit $\mathrm{Wm}^{-1} \mathrm{~K}^{-1}$ range. Polymers, plastics and organic materials range in the tenths of $\mathrm{Wm}^{-1} \mathrm{~K}^{-1}$ regime. Typical thermal insulators (for an overview, see Table 1) and related products exhibit $\lambda$ values which are well below 0.1 $\mathrm{Wm}^{-1} \mathrm{~K}^{-1}$. Table 1 gives an overview over the performance of common insulation materials based on their respective $\lambda$-values: conventional insulation materials highlighted in red have typical lambda-values on the order of $0.030-0.040 \mathrm{Wm}^{-1} \mathrm{~K}^{-1}$. Several definitions of the term superinsulation are commonly used. A misleading and rather meaningless one is based on the total heat transfer coefficient or U-value of a well-defined insulating layer (single workpiece or element). It refers simply to a thick layer of high total thermal resistance. This is of course a poor definition because there is no correlation with the materials insulation performance (per unit thickness). It makes much more sense to adhere to a more meaningful thermal conductivity-based definition rather than a resistance/workpiece specific one. Probably the most commonly encountered definition for superinsulating materials sets the mark at a $\lambda$-value of $0.025 \mathrm{Wm}^{-1} \mathrm{~K}^{-1}$ ). High performance foam insulation such as polyurethane or phenolic resins define a transitional area between conventional and superinsulation products (see Table 1). In our opinion it is today more meaningful to set the limit for superinsulation materials at $0.020 \mathrm{Wm}^{-1} \mathrm{~K}^{-1}$, a definition which we are going to adhere from here on after. The main reason for this choice of limits is that it restricts the use of the term to truly advanced insulation materials and solutions which are intrinsically different from conventional foam and fiber products. Our proposed definition of the term is synonymous with state-of-the-art technology and/or materials. According to this definition, the group of superinsulators highlighted in turquoise in Table 1 then comprises only three kinds of products: aerogels, vacuum insulation panels (VIP) and vacuum glazing (VG). They will be discussed in more detail below.

Vacuum insulation panels and vacuum glazing offer outstanding thermal resistance because evacuation of the porous core material or the glazing cavity respectively results in a drastic reduction of heat transport by gas molecules. Aerogels on the contrary are non-evacuated 
Table 1 Overview of insulation materials according to their ambient thermal conductivities: conventional (Top five) and superinsulation materials and components (bottom three ) can be classified by their respective thermal conductivity values

\begin{tabular}{|c|c|c|}
\hline Insulation product & Chemical composition & $\lambda_{\mathrm{amb}}\left(\mathrm{Wm}^{-1} \mathrm{~K}^{-1}\right)$ \\
\hline Mineral wool & Inorganic oxides & $0.034 \ldots 0.045$ \\
\hline Glass wool & Silicon dioxide & $0.031 \ldots 0.043$ \\
\hline Foam glass & Silicon dioxide & $0.038 \ldots 0.050$ \\
\hline Expanded polystyrene (EPS) & Polymer foam & $0.029 \ldots 0.055$ \\
\hline Extruded polystyrene (XPS) & Polymer foam & $0.029 \ldots 0.048$ \\
\hline Phenolic resin foam & Polymer foam & $0.021 \ldots 0.025$ \\
\hline Polyurethane foam & Polymer foam & $0.020 \ldots 0.029$ \\
\hline Silica aerogels & $\mathrm{SiO}_{2}$ based aerogel & $0.012 \ldots 0.020$ \\
\hline Organic aerogels & Aerogels derived from organic compounds & $0.013 \ldots 0.020$ \\
\hline Vacuum insulation panels (VIP) & Silica core sealed and evacuated in laminate foil & $0.003 \ldots 0.011^{(*)}$ \\
\hline Vacuum glazing (VG) & Double glazing unit with evacuated space and support pillars & $\begin{array}{llll}0.0001 \ldots & \ldots .0005^{(\#} \\
0.003 & \ldots & 0.008^{(\# \#)}\end{array}$ \\
\hline
\end{tabular}

Phenolic and polyurethane foams mark the transition area (italics)

This Table is adapted from [7], chapter 26

(*) Vacuum insulation panels age with time. As the pressure inside the evacuated element rises because of envelope permeability, so does the thermal conductivity of the core materials. Equivalent conductivity values of 30 year aged VIPs depend strongly on the product and materials used and are typically on the order of $0.007-0.012 \mathrm{Wm}^{-1} \mathrm{~K}^{-1}$

(\#) Vacuum glazing performance (in terms of equivalent thermal conductivity) determined from typical U-values on the order of $0.5-0.3 \mathrm{Wm}^{-2}$ $\mathrm{K}^{-1}$ and a thickness of the evacuated gap $(\mathrm{d}=0.3 \ldots 1.0 \mathrm{~mm})$ without taking into account the thickness of the glass panes

(\#\#) $\lambda$-values determined from typical $\mathrm{U}$-values $\left(0.5 \ldots 0.3 \mathrm{Wm}^{-2} \mathrm{~K}^{-1}\right)$ and the total thickness $\mathrm{d}$ ' $=10 \ldots 16 \mathrm{~mm}$ under consideration of the window panes

superinsulators. Their low thermal conductivity is correlated with the pore structure of these materials. Before briefly recalling the effect of the unique structural features of aerogels on heat transport, let us recapitulate the underlying heat transfer mechanisms. Generally, heat is transferred by conduction, convection and radiation. In porous materials there are five possible contributions to the total heat transfer, namely:

- conduction through the solid material,

- conduction through the pore medium (interstitial fluid e.g. air, water)

- convective transport by the pore medium,

- radiative transport from solid surfaces through the pore fluid,

- radiative transport from the solid through the solid network or bulk.

Superinsulating $\mathrm{SiO}_{2}$ aerogels are low-density (typically in the $0.08-0.2 \mathrm{gcm}^{-3}$ range) nanostructured solids with a porosity $>90 \%$ and typical mesopore diameters between 4 and $20 \mathrm{~nm}$. Those mesopores can add up to more than $90 \%$ of the total pore volume. Aerogels owe their extremely low thermal conductivity to the combination of low density and small pores. In other words, the small pores effectively limit conductive and convective gas transport, the low density on the other hand implies that the solid network is delicate providing only limited pathways for conduction though it. Several research groups have studied thermal insulation aspects of aerogel materials in great detail, the leading contributions in the field coming from the group of Fricke, Reichenauer, Weinläder at the Bavarian Center for Applied Energy Research ZAE (see [7], chapter 21). In the following, let us briefly recapitulate the heat transfer pathways in aerogels.

On one hand, convection by the pore fluid i.e. air is reduced already significantly in porous materials with micrometer pore sizes (such as polymer foam insulators) so that only conduction and radiation remain. Because of the small pore sizes however, the conductive heat transfer by the pore fluid, in this case air, equals no longer that of a free gas but follows the Knudsen formula [10] and thus results in an effective gas conduction contribution to the total thermal conductivity much lower than for a free gas. This condition is met when the mean-free path of the gas molecules is effectively constrained by individual pore walls. The problem of simultaneous conduction and radiation between parallel plates is formulated in terms of an integro-differential equation which can only be solved numerically [11]. For semi-transparent grey materials like aerogels, analytical solution based on the concept of effective emissivity have been proposed [12]. Radiative transfer through the pore fluid is comparable to a 
conventional foam insulation material and depends strongly on the density (or more precisely the network connectivity which is directly linked to the density). Radiative heat transfer through the solid network is often neglected but can sometimes represent a few tens of $\%$ of the total thermal conductivity in aerogels. This contribution is extremely temperature dependent and can become dominant at elevated temperature and in ultra-low density aerogels. Under ambient conditions, the conductive (phonon) heat transfer through the bulk solid skeleton is the dominant contribution for mesoporous aerogels of raw densities $>200 \mathrm{~kg} \mathrm{~m}^{-3}$. Its magnitude strongly depends on the nanostructure as well as the bulk density. An expression for the thermal conduction $\lambda_{\text {solid }}$ in a solid is known from the kinetic transport theory,

$\lambda_{\text {solid }}=\frac{1}{3}\left(\mathrm{c}_{\mathrm{e}} \ell_{\mathrm{e}} \mathrm{v}_{\mathrm{e}}+\mathrm{c}_{\mathrm{ph}} \ell_{\mathrm{ph}} \mathrm{v}_{\mathrm{ph}}\right)$

where $\mathrm{c}$ is the specific heat capacity per unit volume in $\mathrm{Jm}^{-3} \mathrm{~K}^{-1}, \ell$ the mean free path and $\mathrm{v}$ is the velocity with the subscripts denoting electronic (e) and phononic (ph) contributions. For electrical insulators such as $\mathrm{SiO}_{2}$ the electronic term in Eq. 1 can be neglected so that conduction is mostly due to phonons. The propagation of phonons in a solid skeleton is determined by the network tortuosity as a pathway for conduction. For silica aerogels consisting of $\mathrm{SiO}_{2}$ particles generally in the 3-7 nm size range, Bernasconi et al. [13] found that phonon heat transport can be attributed to particle and molecular oscillations/vibrational modes. Scattering techniques such as SAXS and SANS measurements have often been used to correlate the overall network structure of aerogels with their thermal transport properties [14-16].

Most commercially relevant superinsulating $\mathrm{SiO}_{2}$ aerogels have densities between 80 and $200 \mathrm{~kg} \mathrm{~m}^{-3}$. Their thermal conductivity values are dominated by conduction through the solid silica particle network at high densities and a combination of radiation and gaseous conduction through the air inside the pores at low densities. To produce the lowest conductivity materials it is necessary to find an optimum between those two types of contributions. It seems apparent that the areogel density has established itself as a central parameter in the discussion of thermal transport properties of these materials. Note that for reasons of clarity and simplicity we are basing our discussion solely on room temperature thermal conductivity values. They are relevant for ambient applications, which, led by building insulation, are representative of the main share of the world's insulation markets. Because of a growing interest in superinsulation products, we shall also provide a brief description of the other two evacuated superinsulation systems which are complementary to areogels namely vacuum insulation panels and vacuum glazing to complete the picture.
2.2 Pressure dependence of the thermal conductivity $\lambda$

The idea of achieving superinsulating properties by evacuating a vessel and thus limiting gaseous heat transport is not exactly a novel concept: the first Dewar flask, an evacuated glass bottle, was invented by Sir James Dewar more than 100 years ago. The space inside the glass receptacle is evacuated to about $10^{-4} \mathrm{~Pa}\left(10^{-6}\right.$ Torr) in order to eliminate gaseous convection and conduction. The inner glass surfaces are coated with an IR reflecting thin metal film which reduces radiative heat transport. One realizes quickly that in the case of an evacuated vessel, a high quality vacuum is necessary to curb gaseous heat transport. However, if a porous material was to be placed inside and evacuated, heat transfer by gas molecules is already effectively suppressed at much higher pressures (lower quality vacuum levels). In porous solids, the gaseous heat transfer is determined by the number density (pressure) of gas molecules as a transfer medium as well as by the number of "walls" or solid skeleton connection pathways between hot and cold sides. At a high pressure, the mean free path of the gas molecules is much smaller than the size of the pores. This means that the collision (momentum transfer) between the gas particles is limiting the total heat transfer. Under atmospheric conditions, this is true for most conventional porous insulation materials. If one were now to reduce the gas pressure by evacuation, the gaseous conductivity remains more or less constant until the mean free path of the gas molecules attains values which are on the order of the size of the pores of the solid. At this point, communication or heat exchange through gas molecules drops significantly because of collisions with the pore walls. This means that an evacuated solid with small enough pores can become a superinsulating material.

Figure 3 shows the effect of the pore size on the pressure dependence of the effective thermal conductivity. The dotted black line labeled "standing air" is the thermal conductivity of pure air at a given pressure without taking into account convection, i.e. a situation in which the air is kept stationary and gas flow induced thermal transport is negligible. A standard polymer foam (blue curve) insulation material such as extruded polystyrene (XPS) has typical pore sizes in the tens to hundreds of micron range. Mesoporous materials such as aerogels or fumed silica (red and green curves respectively) offer pore sizes in the sub $100 \mathrm{~nm}$ range. One observes that with increasing pore sizes, the vacuum must be pushed to a lower pressure to eliminate the gas-phase conduction contribution to the overall thermal conductivity. For aerogels and fumed silica for example, the $\lambda$ vs. $p$ curve reaches its minimum value around $30 \mathrm{hPa}$ (mbar). An XPS foam with significantly larger pores would require evacuation down to pressures below $0.1 \mathrm{hPa}$. In the absence of a porous solid (such as for 


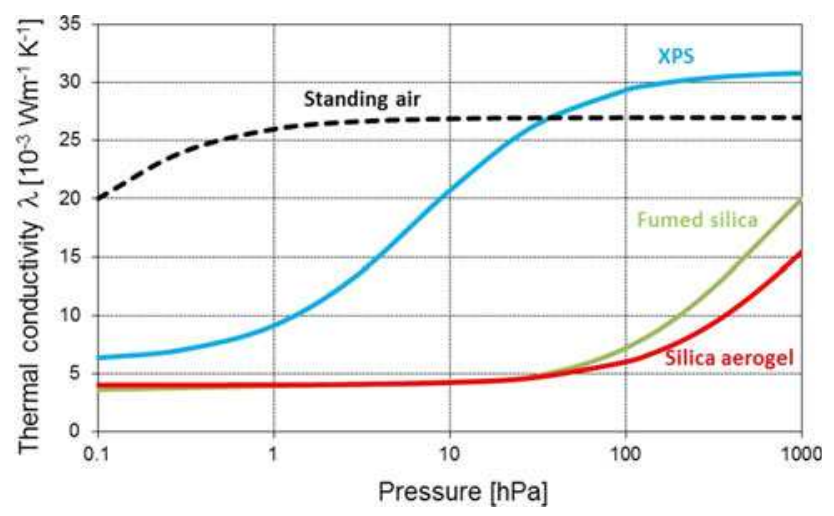

Fig. 3 Schematic representation showing the effect of the system pressure on the total ambient thermal conductivity at $25{ }^{\circ} \mathrm{C}$

example inside the cavity of a vacuum glazing unit), vacuum levels below $10^{-3} \mathrm{hPa}$ are required to completely eliminate gas-phase heat transfer.

For standard applications, i.e. at near ambient temperatures, the gaseous conduction is typically the largest contributor to the overall heat transport. Nevertheless, when creating the perfect superinsulating material or component, the conduction through the bulk material needs to be minimized as well, which is synonymous with the requirement of a high porosity (and ideally an intrinsically low bulk conductivity) of the evacuated solid. In a similar manner, radiative transport needs to be taken into account. The latter is particularly relevant at elevated temperatures. Having covered the basics of evacuated superinsulation, let us briefly zoom in on the two most typical systems and their applications: Vacuum Insulation Panels (VIPs) and Vacuum Glazing (VG).

\subsection{Evacuated superinsulation systems}

Vacuum Insulation Panels (VIPs) and Vacuum Glazing (VG) are the incarnations of the concepts shown in Fig. 3. For a VIP, a core of a pressed mesoporous powder, typically fumed silica, is wrapped in a multilayer laminate barrier foil and evacuated to submillibar $(<1 \mathrm{hPa})$ pressures and sealed [17]. The barrier foil consists of a multilayer polymer foil sandwich construction with $\mathrm{Al}$ diffusion barrier layers in between them. A vacuum glazing unit consists of two glass panes separated by a very thin $(0.2-0.8 \mathrm{~mm})$ gap and held together by an absolutely hermetic edge seal. A cavity pressure on the order of $\sim 10^{-1}$ $10^{-2} \mathrm{~Pa}\left(10^{-3}-10^{-4}\right.$ Torr $)$ is required for optimal $\mathrm{VG}$ insulation performance; at higher pressures the thermal performance rapidly deteriorates.

The main advantage of both types of evacuated superinsulation systems is their extreme performance. Substitution of conventional double glazing units with vacuum glazing (VG), can bring about a reduction of a factor of 2-5 of heating and cooling energy per area of glazed building surface [18]. Vacuum insulation panels offer a 4-10 times higher simulation performance per $\mathrm{cm}$ of material thickness used when compared to standard insulation materials such as polymer foams or mineral/glass wool.

Both VIP and VG are nevertheless quite sensitive to damage and subject to aging effects [19]. This can lead to a partial or complete loss of the thermal insulation performance: VIP barrier foils are extremely sensitive to mechanical piercing or other forms of damage (aging, loss of integrity, delamination). The great sensitivity and aging effects which are due to gas permeability (as the pressure inside the panel rises, so does the thermal conductivity) are among the main disadvantages of vacuum insulation. Where suitable, VIP are extremely powerful insulation systems if properly implemented and mounted. Current VIP-technology uses mostly pyrogenic silica as a core material. It is the only evacuated system available today which can fulfill the requirements for long-term applications in building insulation with a service life period of 30 years or more [20]. Other mineral-based materials such as glass fibers, porous minerals or expanded clays are used as alternative inexpensive core materials and/or fillers. For vacuum glazing, the situation is quite similar. The high vacuum environment must be maintained inside the glazing cavity over a prospected service life period of 30 years without the need for additional pumping or servicing. Those stringent requirements make a practical realization of vacuum glazing on a commercial scale a Gordian task. From a practical point of view, the lack of suitable (vacuum compatible, hermetic, glass-to glass, full perimeter) edge sealing technologies have inhibited the large scale commercial realization of superinsulating vacuum glazing systems with the desired performance. Currently the only commercial VG products which are being manufactured in Asia (Japan, China and Korea) have an insulation performance which is significantly inferior to that of Ar or Kr filled state-of-the-art commercial double glazings. They are being sold in the Asian markets as a replacement for single pane glass. Nevertheless, VG still offers great potential to revolutionize the glazing and building insulation markets, however new, advanced edgesealing and integrated manufacture concepts are necessary. At best, the realization and implementation of distinct technological advances [21] could reach the public markets within the next 10 years. Alternative highly insulating translucent glazing systems are aerogel-filled windows which are already available on the market.

\subsection{Aerogel based superinsulation}

Insulation products are being sold worldwide for a number of applications such as building construction and heating, ventilation and air-conditioning (HVAC) systems, industrial 
processes as well as niche markets and high performance products or systems. The latter sector holds the main market share of superinsulation products. Generally, an insulating layer reduces heat transfer between two workpieces held at different temperatures and thus helps to reduce energy losses. Without proper insulation, these losses need to be compensated by an additional input of energy into the system. Apart from the energy savings and the related reduction in $\mathrm{CO}_{2}$ emissions, insulation also offers additional comfort: in an insulated building or industrial piping system one encounters a more uniform temperature distribution which results in a more agreeable living experience or improved plant operation respectively. Generally, aerogel based superinsulation products can be categorized into the following three classes which differ in the manner in which the aerogel is incorporated into a material, system or component.

- Monolithic aerogels: large $(>1 \mathrm{~cm})$, homogeneous blocks of a particular aerogel material.

- Divided materials: finely divided aerogels are random "monolithic" pieces or crumbs of aerogel with typical diameters below $1 \mathrm{~cm}$ for granules and $1 \mathrm{~mm}$ for powders.

- Composite materials: homogeneous or heterogeneous aerogel phases with at least one additive incorporated either into the gel matrix (e.g. during synthesis) or added to the gel as a second distinct phase such as fibers, blankets, a fleece or also by a subsequent modification by compounding.

Monoliths are primarily obtained via supercritical drying. The synthesis of large monolithic pieces of aerogels is both time and cost intensive. For this reason, there are virtually no commercial monolithic aerogel products available at the moment. Today's top-selling commercial products are either granular or blanket-type materials. The three classes of aerogel morphologies will be discussed in more detail in the following chapter.

\subsection{Market considerations}

The world's insulation markets [22] are a profitable industry trade with annual projected growth rate around $5 \%$ when measured by sales between the years 1997-2008. Figure 4 gives an overview of the global markets from 1997 until today and the projected annual volumes until the year 2017 , sorted by product species: the total of sold insulation performance in units of $\left(10^{9} \mathrm{WK}^{-1}\right)$ is represented by the thick black curve with black squares. The thick red line with red squares represents the dollar value of total insulation sold per year in billion US\$. This curve again shows a more or less continuous $5 \%$ annual growth rate, with a below average performance from 1997 to 2002, a superior performance between 2002 and 2007

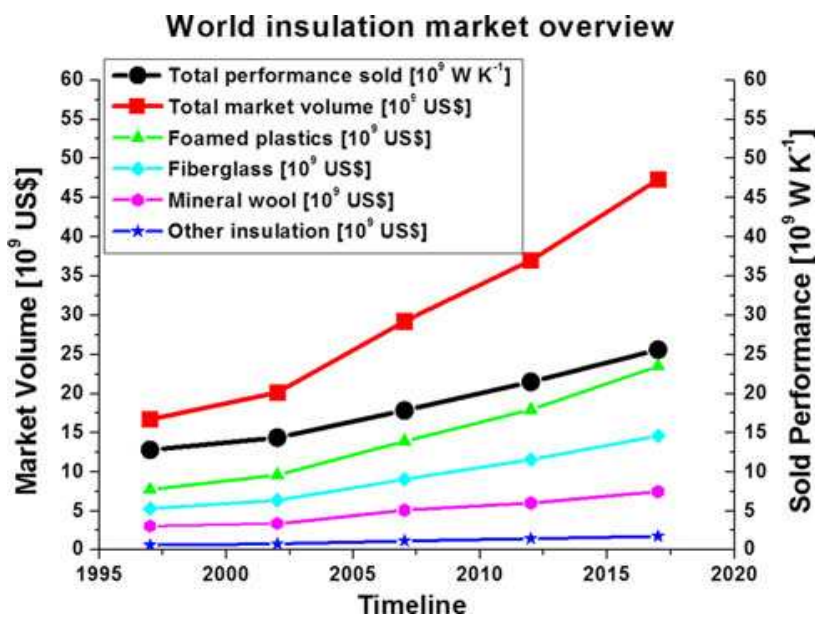

Fig. 4 Overview over global thermal insulation markets including projected developments and respective market shares of individual insulation product sectors (From [7], chapter 26)

and finally a slight deterioration in sales after 2007 which is partly due to the sub-prime real-estate initiated global economic crisis. The slope of the thick black thick line is steeper than that of its grey analogue, the reason for this being an increasing cost per unit of insulation product performance. The finer lines in black represent the individual insulation product sectors which in total add up to the total volume (black squares) which has just been discussed. On a global scale, foamed plastics (black triangles) hold the majority of the total insulation products market with a share of approximately $48 \%$. Until 2017 they are expected to slightly extend their leading position to approximately $50 \%$ market share. Fiber glass (black circles) and mineral wool products (black open circles) hold second and third place with roughly 31 and $17 \%$ shares respectively. Their particular market relevance is expected to decline slightly over the next decade, covering for the gain of polymer foam products. Depending on location, the respective roles can be redistributed when looking at continental market data. In Western Europe for example, fiberglass products are market leader with an almost $40 \%$ share, followed by extruded polystyrene foam EPS (22\%) and mineral wool $(16 \%)$. Eastern European markets are dominated by mineral wool products which account for almost $48 \%$ of local markets. EPS and fiberglass insulation are worth 29 and $13 \%$ respectively. Such differences in local product hierarchies can be explained to a large part by resource availability and supply arguments.

Going back to the global insulation data, niche products, which are denoted "other insulation" in the graph, account for less than $4 \%$ of the global market. Still, this sector has an annual turnover in excess of 1.1 billion US\$ (2008). In this sector, aerogels account currently for approximately $5 \%$. 
In 2008, aerogel materials and products sales were in excess of 80 million US\$ [23], with thermal insulation products making up for approximately $60 \%$ of this number or 50 million US\$. The aerogels sector being an emerging market, tremendous annual growth rates from 50 to $75 \%$ have been seen in recent years and similar developments are expected for the near future. In 2004 for example, global aerogel sales accounted for only 25 million US\$. Recent market studies project worldwide sales of aerogel products in excess of 500 million US\$ for the year 2013. This development is consistent with a number of new production facilities which have recently been coming online. These developments shall be taken as a sign that global markets are ready for high-priced, aerogel based superinsulation products. It is expected that, starting from today, the aerogel markets will continue to grow much more rapidly than the "conventional" insulation business for at least a decade up to the point when markets will begin to saturate. Saturation will certainly depend on a continuous reduction of product cost which goes hand in hand with increasing production capacities. A current benchmark value for a cubic meter of silica aerogel is on the order of 4,000 US\$. With increasing commercialization, this value could drop below the 1,500 US\$ mark by the year 2020. To gain more insight into the materials side, let us discuss superinsulating aerogels, their chemical composition and synthesis as well as application-geared improvement strategies.

\section{Superinsulating aerogel materials}

\subsection{Overview of common chemical synthesis methods}

Silica aerogels are the most widely studied aerogel materials and the only ones "really" available commercially today. For this reason, we are limiting the discussion of chemical synthesis methods to this class of materials. Generally, the most widely used sources of silicon, the so-called precursors are alkoxysilanes such as tetraethoxysilane or tetraethylsilicate TEOS and tetramethoxysilane TMOS [24, 25] or the inorganic sodium silicate (waterglass) [26]. More recently, waste products such as oil shale ash [27], rice husk ash [28, 29] or fly ash [30] have been investigated as inexpensive alternatives. From a more general point of view, such exotic precursors make part of an eco-design strategy for silica aerogels elaboration [31]. For reasons of simplicity we focus here on the description of the two more common waterglass and alkoxide precursors only:

Both precursors allow either single or two-step preparation. In a single step reaction, the formation of colloidal particles or larger silica building blocks (generally called clusters [32]) and their random aggregation to form a threedimensional network structure, the gel, are occurring simultaneously. In a two-step process, a colloidal particle solution, the sol, is obtained through hydrolysis or acidification/ion exchange respectively. Such a sol state can be stable over weeks or months, because the aggregation of colloids is inhibited through repulsive interparticle potentials (surface charges). Partial neutralization of the colloid surface charges induced by base addition typically induces gelation in the second step. This happens when the $\mathrm{pH}$ of the solution is near the isoelectric point (pI) of the metal oxide sol. Because sol formation and gelation are well separated, two step processes are in general more versatile and allow better control over the resulting gel network morphology. The main chemical difference between waterglass and alkoxide based methods is the nature of the solvent medium as described here-after.

Sodium silicate is an inorganic, water soluble compound and hence waterglass based gels are typically synthesized in aqueous solution. It is prepared industrially by reacting quartz sand with soda lime at high temperatures ( $\sim 1,100{ }^{\circ} \mathrm{C}$ ) and dissolving the resulting solid "cullet" and finally adjusting the $\mathrm{pH}$-value/sodium content by addition of sodium hydroxide [33]. One important fact to keep in mind is the chemical complexity and diversity of the silicate system: silicic acid $\left(\mathrm{Si}(\mathrm{OH})_{4}\right)$ and silicate as an acid base pair do not behave like typical inorganic mineral acids due to its complex isomerism and structure.

Single step silica hydrogel formation is effected by partial neutralization of sodium silicate to a $\mathrm{pH}$ value in the range of 5-9, resulting in rapid gelation times (region II, Fig. 6). If a waterglass solution is acidified to $\mathrm{pH}$ values below 3.5 (by acid addition or ion exchange), gelation times are extremely long. The subsequent addition of base to a point near electro-neutrality will initiate the formation of a gel in a two-step process (Fig. 5). Under acidic conditions, waterglass exists mainly in its protonated form that is as silicic acids. The simplest forms are metal-silicic acid $\mathrm{H}_{2} \mathrm{SiO}_{3}$ and its hydrated form orthosilicic acid $\mathrm{H}_{4} \mathrm{SiO}_{4}$. Even at low $\mathrm{pH}$, silicic acid tends to dimerize, forming $\mathrm{H}_{6} \mathrm{Si}_{2} \mathrm{O}_{7}$ from orthosilicic acid and $\mathrm{H}_{2} \mathrm{Si}_{2} \mathrm{O}_{5}$ from metasilicic acid. Trimers such as $\mathrm{H}_{8} \mathrm{Si}_{3} \mathrm{O}_{10}$ are formed by addition of another molecule of silicic acid [34]. The stepwise condensation of small silicic acid oligomers is believed to produce mostly ring-like structures with 3-6 silicon atoms and a largest possible number of $\equiv \mathrm{Si}-\mathrm{O}-$ $\mathrm{Si} \equiv$ linkages. Numerical calculations [35] predict a constant increase in the enthalpy of formation of only about 17 $\mathrm{kJ} / \mathrm{mol}$ for each additional molecule of $\mathrm{H}_{4} \mathrm{SiO}_{4}$ added. For this reason, the nucleation of colloidal silica particles is believed to be occurring around a critical cluster size containing 3-6 silicon atoms. The effect of the $\mathrm{pH}$ on the polymerization or condensation of silicic acid has been 


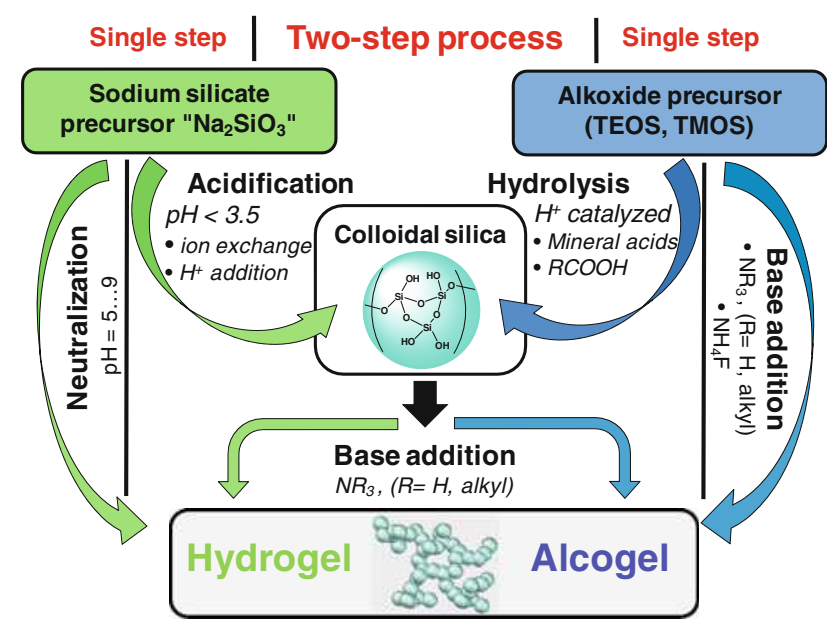

Fig. 5 Schematic overview of the two main synthesis paths of nanostructured silica gels from sodium silicate and silicon alkoxides (i.e. alkoxysilanes) using either direct (single step) or hydrolysis/ condensation (two-step) methods

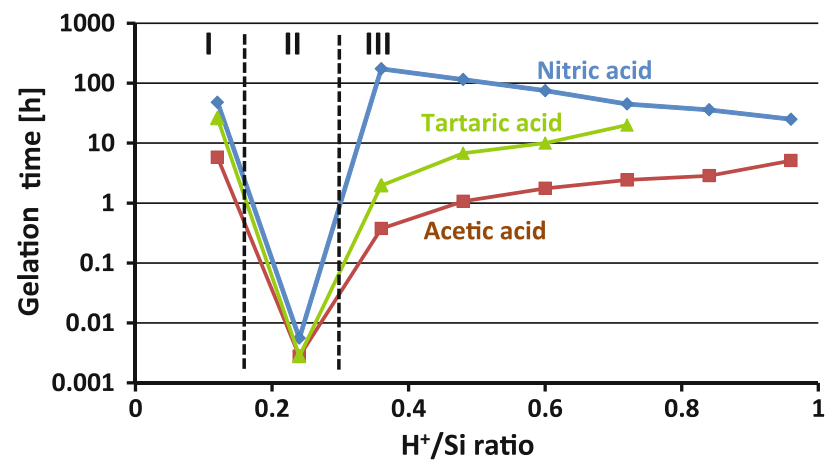

Fig. 6 Influence of the amount of acid added on the gelation time for a $0.7 \mathrm{M}$ sodium silicate solution (expressed as $\mathrm{Na}_{2} \mathrm{SiO}_{3}$ ). Note that under both basic (I) and acidic conditions (III) the colloidal solutions are highly stable

known for well over 50 years: at both low and high $\mathrm{pH}$, the reaction rates are extremely low (repulsion). In the range from $\mathrm{pH} 4-10$, polymerization is much faster with the highest rates observed around $\mathrm{pH}=8.6$ [36].

This is illustrated with three different acids shown in Fig. 6: acidic and basic regimes I and III. When passing the point of neutralization (region II, $\mathrm{H}^{+} / \mathrm{Si} \sim 0.28$ ), the addition of minute amounts of a strong mineral acid such as $\mathrm{HNO}_{3}\left(\mathrm{pK}_{\mathrm{a}}=-1.5\right.$, blue line) results in an over four order of magnitude increase in the gelation time. Beyond the point of neutralization, the addition of organic carboxylic acids such as tartaric and acetic acids $\left(\mathrm{pK}_{\mathrm{a} 1}=2.96\right.$ and 4.8 , green and red lines) leads to a significantly slower increase in the respective gelation times. These findings are primarily attributed to the different degree of dissociation of the three acids, i.e. a larger amount of free protons $\left(\mathrm{H}_{3} \mathrm{O}^{+}\right)$ in the case of nitric acid which causes a more rapid decrease of $\mathrm{pH}$ into the acidic regime (III) and thus increased stabilization of silicic acid colloids. Aside from Brønsted acidity, the counterion (nitrate, acetate, tartrate etc.) also influences the gelation kinetics. The addition of salts such as $\mathrm{NaCl}$ is known to effectively screen surface charges surrounding individual particles which also accelerates gelation [37]. The role of the acid's counter anion (the corresponding base) coordinating to the silica surface is less studied but certainly also affects the kinetics due to a more or less effective screening and surface coordination.

Tetraethoxysilane (TEOS) or tertramethoxysilane (TMOS) are the most well know representatives of the class of saturated silicon alkoxides. They are most typically produced by alcoholysis of silicon tertrachloride $\mathrm{SiCl}_{4}$ with the corresponding anhydrous alcohol. They are also classically obtained directly from silicon metal.

$\mathrm{SiCl}_{4}+4 \mathrm{R}-\mathrm{OH} \rightarrow \mathrm{Si}(\mathrm{OR})_{4}+\mathrm{HCl}$

$\mathrm{Si}+4 \mathrm{R}--\mathrm{OH} \rightarrow \mathrm{Si}(\mathrm{OR})_{4}+2 \mathrm{H}_{2}$

with $\mathrm{R}=--\mathrm{CH}_{3}$ (TMOS) or $--\mathrm{C}_{2} \mathrm{H}_{5}$ (TEOS).

Both, TEOS and TMOS find wide use in the synthesis of silica-based materials such as mesoporous materials [38], aerogels [39], films [40] and more recently organically modified silica (Ormosil) [41, 42] and composite materials [43, 44].

In contrast to waterglass, the use of alkoxides requires the "activation" of the precursor: the hydrolysis of silicon alkoxides in a mixture of water and their parent alcohol leads to silicic acid oligomers [45]. The exemplary case of the complete hydrolysis of TEOS with catalytic amounts of acid yielding o-silicic acid is shown formally in Fig. 7 below.

However, in reality silicic acid monomer forms are known to condensate rapidly (formation of dimers, trimers etc.) via siloxane bonding through water $(\equiv \mathrm{Si}-\mathrm{OH} / \equiv \mathrm{Si}-$ $\mathrm{OH}$ reaction) and/or alcohol ( $\equiv \mathrm{Si}-\mathrm{OH} / \equiv \mathrm{Si}-\mathrm{OR}$ reaction) condensation. Hence a more or less complete hydrolysis of silicon alkoxides leads to the formation of silica oligomers and eventually a colloidal silica solution or sol. The chemical nature, diversity and composition of such a sol and the resulting aerogels compare quite well to materials obtained by acidificication (or ion exchange) of aqueous
Fig. 7 Complete hydrolysis of tetraethoxysilane (TEOS) by acid catalysis

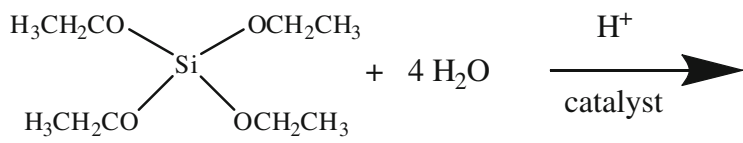

TEOS<smiles>C[14CH2]CO</smiles>

o-silicic acid 
sodium silicate [39] with two main differences-the solvent medium and the presence of residual unhydrolyzed alkoxy groups which are isotropically distributed within the silica phase. Note that the use of the term "hydrolysis" is also sometimes used incorrectly in conjunction with sodium silicate systems where no actual chemical hydrolysis is involved in the activation/sol formation.

Just like in the waterglass case, a two-step alkoxyde process permits to separate hydrolysis/condensation reactions from network formation/gelation [46] and thus, permit to "control" in a better way the texture of the dried material. The classical two-step process is often referred to as acid/base catalyzed synthesis. Hydrolysis and condensation of so-formed silicic acid oligomers is initiated by catalytic amounts of acid and is believed to follow an $\mathrm{SN}_{1}$ limited mechanism with a trialkoxysiliconium cation as a rate determining transition step [47]. The sol formed in this way carries a certain amount of positive surface charge (e.g. in the form of protonated silanol groups) which leads to repulsion of individual colloidal particles causing their kinetic stabilization. Base addition in catalytic amounts neutralizes these surface charges and initiates gelation in the second step. The kinetics and reaction mechanisms of the hydrolysis and condensation reactions has been widely described in the literature [48, 49]. Nuclear magnetic resonance is a great tool for this type of investigations as it allows a quantitative in situ observation [50] and modelling [51] of the various bonding states (alkyoxyde, silanol, siloxane) of the silicon centers. Small angle X-Ray scattering allows to obtain information about the particle sizes and morphology of sol and gel states during the synthesis reaction [52]. The choice and concentration of base used in both single and two-step alkoxide processes is a central parameter in the synthesis of alkoxide-based gels.

In a single step process, the alkoxide is hydrolysed by a base catalyzed reaction. Typically Lewis bases such as fluorides [53] or mixed ammonium fluoride and hydroxide $[53,54]$ but also alkylamines [55] are used. In the former case, the hydrolysis goes through an $\mathrm{SN}_{2}$ type pathway, that is through nucleophilic attack of the silicon atom. Because hydrolysis/condensation and gelation processes are not separated, the gel morphology of materials produced by single step methods is generally less regular and the pore size distribution is wider and contains a larger fraction of (macro)pores with a diameter $>100 \mathrm{~nm}$. For this reason, aerogels coming out of a two step process are known to exhibit better optical transparency than their single-step analogues [56]. In the aerogel domain, some pre-polymerized TEOS-based precursors can be commercially found. They have been developed from the early nineties on by the French fine chemicals manufacturer PCAS (Longjumeau, France). The corresponding commercial solutions are composed of silica-based oligomers obtained by sub-stoichiometric reaction of TEOS with water in ethanol under mineral acid catalysis [57]. These precursors are named PEDS (for polyethoxydisiloxanes). They are roughly composed of 5-10 monomer units and some ${ }^{29} \mathrm{Si}$ NMR studies have shown that these oligomers appear weakly ramified (with Si-atoms exhibiting 2-4 siloxane bonds) [58]. So-to-say, such precursors are readymade sols for performing the second base-catalysed step at the laboratory scale. Amongst others, they have been widely studied for elaboration of transparent super-insulating silica aerogel panes for highly-efficient doubleglazings [59].

\subsection{Super-insulating silica-based aerogels}

\subsubsection{General overview}

For a long time, aerogels have been defined as nanostructured materials (Fig. 8) obtained exclusively by supercritical drying of sol-gel chemistry derived gels [60]. If the same gels were dried via a subcritical or evaporative route, the resulting materials were often named xerogels [61]. With improved subcritical drying and synthetic strategies developed over the last two decades, materials with very similar structural features when compared to supercritically dried "classical" aerogels can be obtained. Subcritically dried aerogels (assuming they have a low density and a high porosity to qualify as such) are commonly named ambientdried aerogels or ambigels nowadays [62]. Whatever the drying route, it is the sol-gel synthesis which permits to control the aggregation of the precursors and thus to tailor the nanostructuration of the final materials (Fig. 9) and the resulting physical properties. Drying of the silica gels is marginally modifying their nanostructuration but has a strong influence on their morphology because of mechanical

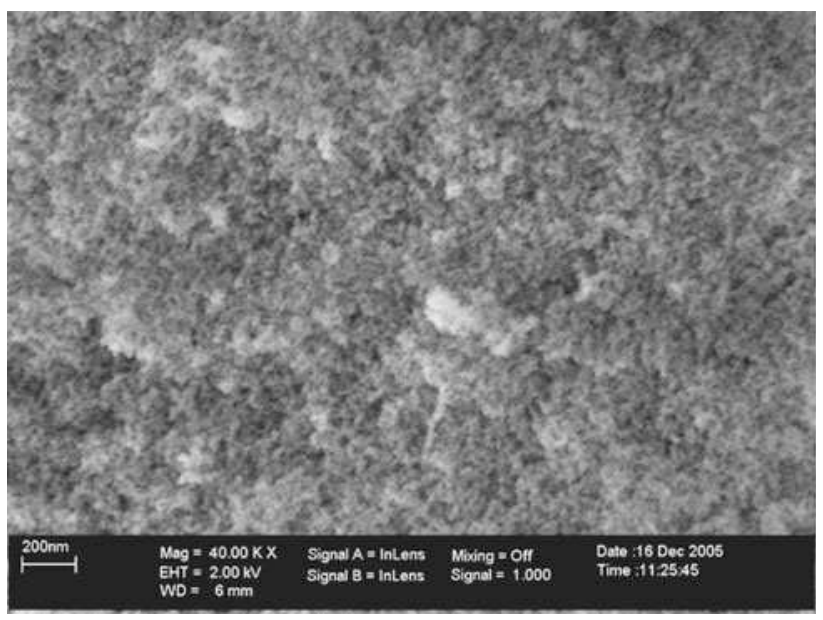

Fig. 8 Scanning Electron Microscopy of silica aerogel presenting a density of $0.18 \mathrm{~g} \mathrm{~cm}^{-3}$ (SEM-FEG microscopy from F. Charlot, INPG-CMTC, Grenoble, France) 


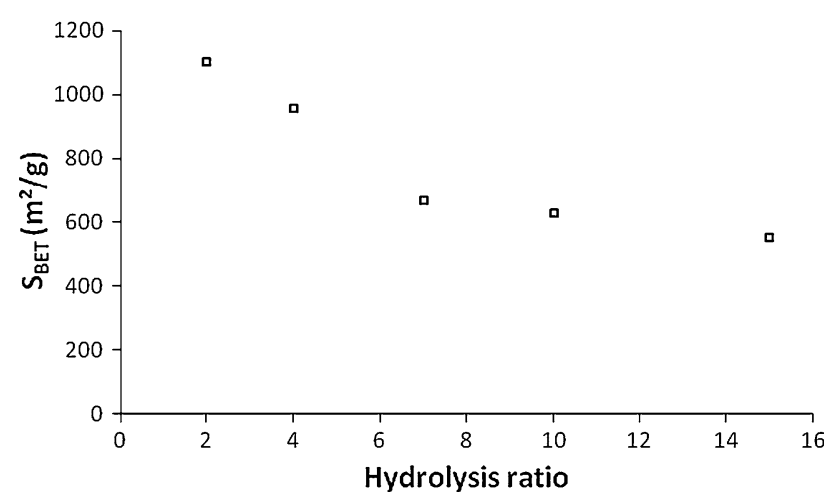

Fig. 9 Illustration of the impact of sol-gel parameters on nanostructuration through the influence of the hydrolysis ratio-defined here as the molar ratio $\left[\mathrm{H}_{2} \mathrm{O}\right] /[\mathrm{Si}]$ - on the specific area of some silica aerogels as measured by BET treatment of $\mathrm{N}_{2}$ adsorption isotherms [67] (Gels synthesized in isopropanol with $70 \mathrm{~g}_{\mathrm{SiO}_{2}} / 1$ under $\mathrm{NH}_{4} \mathrm{OH}$ catalysis, aged in mother liquor at $60{ }^{\circ} \mathrm{C}$ during 5 days and dried with supercritical $\mathrm{CO}_{2}$ )

stresses (shrinkage, warping, cracking,...) [63, 64]. After drying, silica materials can conserve their initial monolithic form but given their friable appearance, they tend to break up into small pieces yielding divided (granular or powdered) silica samples. Whatever its macroscopic shape, an untreated silica aerogel is hydrophilic because of residual silanol groups $(\equiv \mathrm{Si}-\mathrm{OH})$. A typical surface concentration is between 3 and $6 \equiv \mathrm{Si}-\mathrm{OH}$ groups per $\mathrm{nm}^{2}[65,66]$.

All these properties have a strong influence on the thermal characteristics. The effective thermal conductivity is strongly dependent on the aerogel apparent density [68]. Indeed superinsulating silica aerogels with $\lambda<0.020$ $\mathrm{Wm}^{-1} \mathrm{~K}^{-1}$ can only be found within a rather narrow range of densities (Fig. 6), usually located between 0.10 and 0.20 $\mathrm{g} \mathrm{cm}^{-3}$.

Finally, it must be added that the flexibility of the solgel process also permits to disperse particulate matter into the sol to improve both thermal and mechanical characteristics of the resulting insulators [69]: for example, powders and nanoparticules (e.g. C, $\mathrm{TiO}_{2}, \mathrm{ZrO}_{2}$ ) for infrared opacification or fibers (e.g. ceramics, organics, glass) or inorganic clays such as kaolin or attapulgite for mechanical strengthening. More recent activities are focusing on the dispersion of nanofibers to reinforce significantly mechanics without inducing damaging increase of the thermal conductivity [70].

\subsubsection{Monoliths}

Because of its inherent property to minimize capillary stresses, supercritical drying is the royal way to elaborate large monolithic superinsulating silica aerogel plates (Fig. 10). Combining very low thermal conductivity and good optical properties, particularly transparency, such

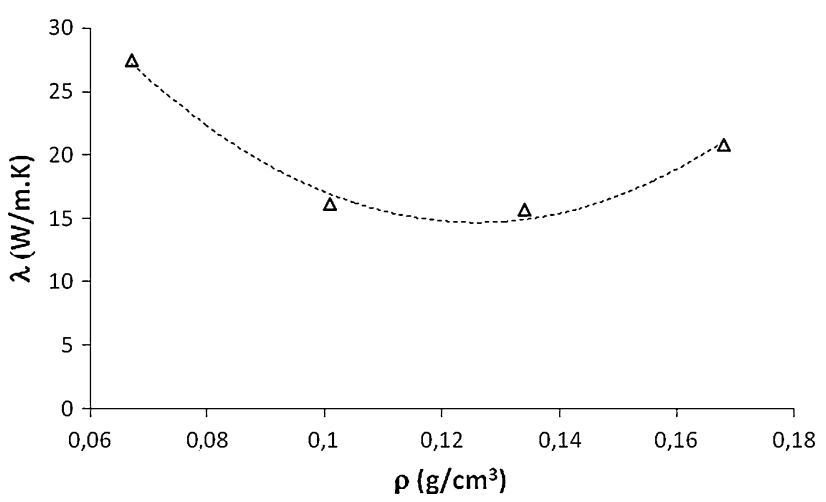

Fig. 10 Illustration of the influence of the apparent density on the effective thermal conductivity $\lambda$ of some monolithic silica aerogels (as measured by the hot-disk method under ambient conditions) [71]

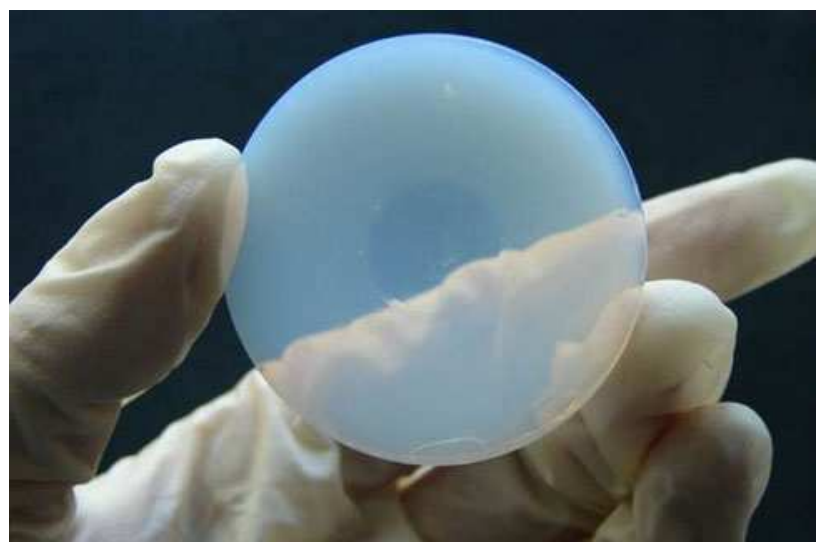

Fig. 11 Example of silica aerogel monolith (sample synthesized by a two-step catalytic process from TEOS and dried with supercritical $\mathrm{CO}_{2}$, presenting a density of $0.13 \mathrm{~g} \mathrm{~cm}^{-3}$ and an effective thermal conductivity of $0.015 \mathrm{Wm}^{-1} \mathrm{~K}^{-1}$ as respectively measured by mercury pycnometry and with the hot-wire method at room temperature)

silica aerogels are of high interest for potential applications in the transparent thermal insulation field [72] (Fig. 11).

\subsubsection{Granular materials}

Even if supercritical drying permits to obtain perfectly monolithic and highly transparent silica-based thermal insulators, the process to obtain such crack-free large plates remains still too far from industrial large-scale commercialization. This was the initial reason why different processes have been studied to develop subcritical routes to access rapid massive commercialization. Among the various studies, ageing of the gels in silica precursor containing solution has permitted to reach room temperature thermal conductivities as low as $0.020 \mathrm{Wm}^{-1} \mathbf{K}^{-1}$ at the laboratory scale [73]. The most efficient routes however which until now have not made it past the pilot scale are based on chemical modification of the pore surface after the gelation 
step [74] and/or employ sylilated precursors (such as MTMS) together with TMOS and/or TEOS within an hybrid sol-gel process [75]. Roughly speaking, it consists in replacing (native) condensable silanols by uncondensable groups as illustrated hereafter in Figs. 12 and 13. It is believed that these chemical methods permit to perform simple evaporative drying at atmospheric pressure without prejudicial densification. At present, some works focused on intensified silylation treatments are in the making, for example silylation in supercritical $\mathrm{CO}_{2}$ [76].

Thanks to the induced spring-back effect [77], thermal conductivities equivalent to these of large silica aerogel plates can be achieved with ambient dried analogues today. Furthermore, as a consequence of these direct/indirect sylilation processes, the dried materials exhibit hydrophobic properties. Indeed, because of replacements of hydrophilic silanols by nonpolar $\equiv \mathrm{Si}-\mathrm{R}$ groups (with $-\mathrm{R}$ being an alkyl group) the hydrophilicity decreases drastically. This has significant consequences on thermal insulation applications under real-life conditions. The main difference between supercritical superinsulating aerogels lies in the fact that so far the subcritical route only permits to obtain granular pieces of material (Fig. 13) as well as, in some rare cases, some small monoliths [78].

As previously described in many papers [79], packed beds of granular beads present effective thermal conductivities slightly larger than their monolithic parents at atmospheric pressure and within the low-vacuum range because of the trapped air in the inter-granular macropores, even if the granules themselves offer the same thermal conductivity values as the monoliths. Of course, the overall packed bed conductivity in this range can be significantly decreased by simple compression and/or packing which reduces the volume fraction of air [80]. It can also be underlined that, still because of the inter-granular macroporosity, without significant external load, under vacuum, effective thermal conductivities of packed beds of granules are generally lower than the ones of their monolithic counterparts [71].

\subsubsection{Aerogel infused blankets}

Within the field of superinsulating sol-gel silica materials, the most recent studies concern fibrous composites. Even if
Fig. 12 Schematic illustration of spring-back effect induced by chemical silylation of the pore walls of the silica gels (top picture: irreversible shrinkage due to siloxane bondings between remaining silanols; bottom picture: partial reversible shrinkage due to replacement of silanols by uncondensable species with $-\mathrm{R}$, an alkyl group)
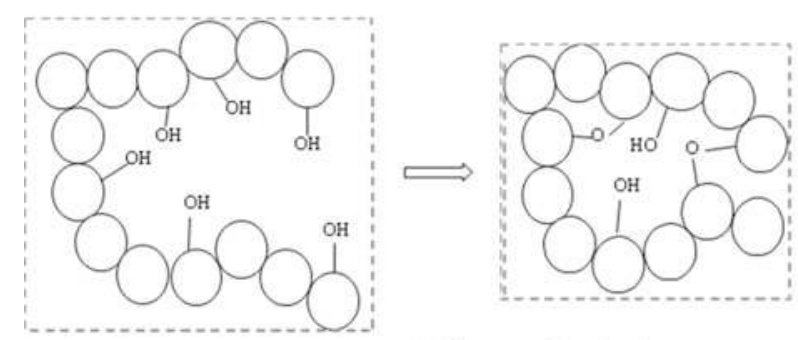

i. Evaporative drying

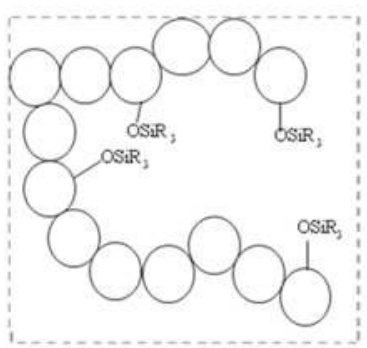

Irreversible shrinkage

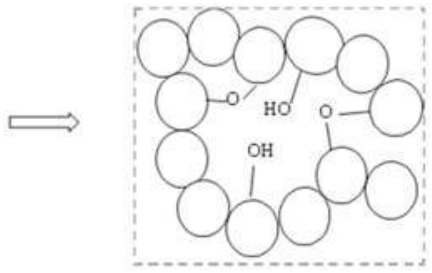

ii. End of the ry ing

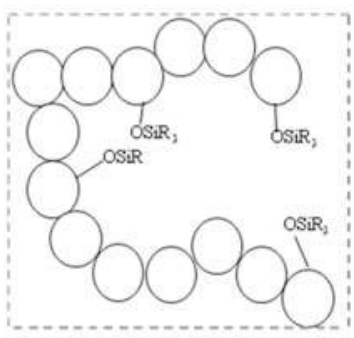

Partially reversible shrinkage
Fig. 13 Experimental demonstration of the silylation with TMCS of: left) silylated sample, right) untreated sample (gels synthesized by a two-step catalytic process from TEOS and dried at $140{ }^{\circ} \mathrm{C}$ during $4 \mathrm{~h}$ )
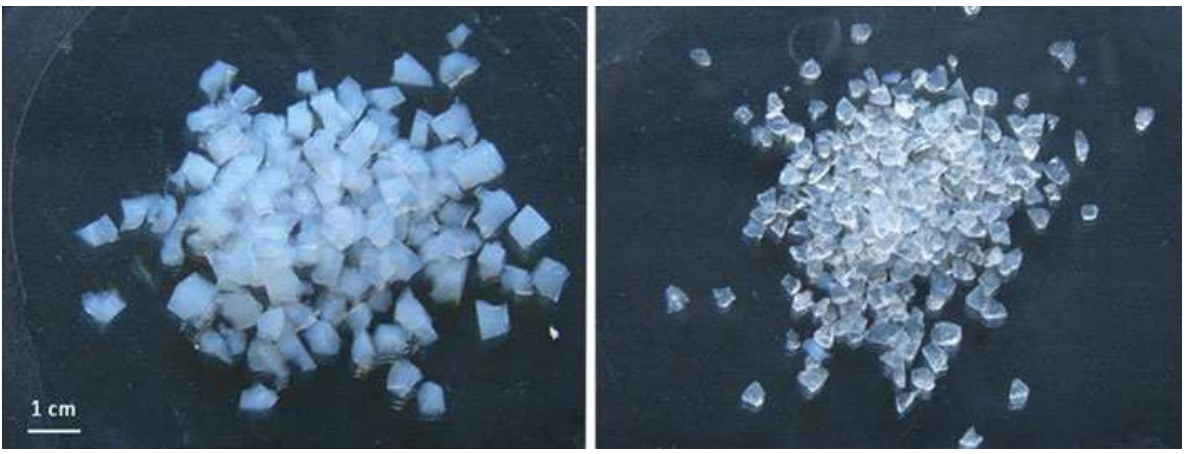
monolithic and granular aerogels can be considered as elastic materials with respect to their mechanical behavior [81], their inherent mechanical limitations prevent them from providing real flexibility. This is the initial reason why brand new composites, such as blanket-type forms, have been developed recently [82]. First, the silica sol is cast onto an ultraporous unwoven fibrous batting (usually but not exclusively a mineral fiber [83]). Generally, the drying of the wet composite is then performed under supercritical conditions but some first attempts of evaporative drying have been reported as well [84]. During evaporation, the silylated gel cracks but the fibers permit to maintain the global cohesion (Fig. 14) while offering macroscopic flexibility (Fig. 15). Further characterizations have shown that the increase of the thermal conductivity under isostatic compression (of 1.2 MPa) can be negligible [85]. At present the main physical drawback of superinsulating aerogel blankets is still their dust release behavior.

\subsection{Hybrid and organic aerogels}

For various reasons, it seems at present that superinsulating solutions at atmospheric pressure could merge from composites and hybrids and, more particularly, from coupling inorganic and organic chemistry. Among others, pure silica systems are mechanically too weak, blankets are dusty, purely organic derived materials are flammable. Combining the advantages from both ends, inorganic-organic composites and/or hybrids could permit to obtain superior superinsulators, particularly from a mechanical and thermo-mechanical compromise point of view.

As an illustration of studies involving organo-mineral composites, the following approaches must be mentioned: (i) preparation of foam-based composites through

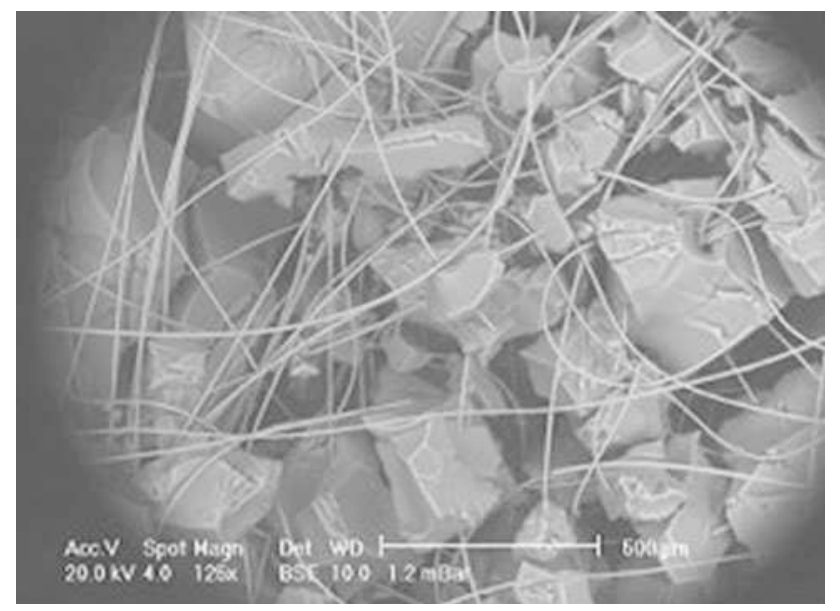

Fig. 14 Typical SEM image of an ambient-dried silica aerogel-based blanket featuring a density of $0.1 \mathrm{gcm}^{-3}$ and an effective thermal conductivity of $0.014 \mathrm{Wm}^{-1} \mathrm{~K}^{-1}$ at ambient conditions, (measured in a guarded hot plate setup at CSTB, Grenoble, France)

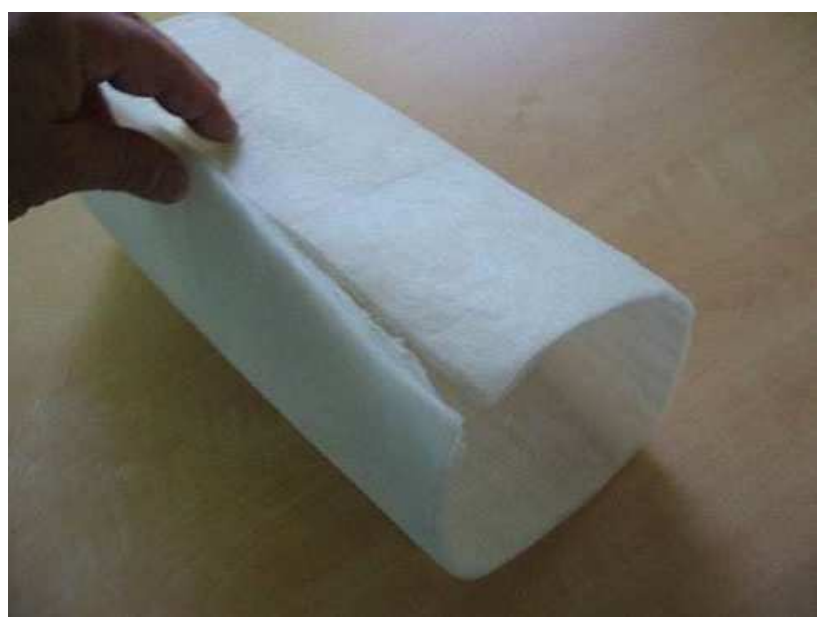

Fig. 15 Photograph of the ambient-dried silica aerogel-based blanket observed in Fig. 14, with courtesy of. Bonnardel P.A, PCAS, Longjumeau, France and Sallée H. CSTB, Grenoble, France

elaboration of superinsulating silica aerogels directly within the pore network of open organic foams (polyolefin, polyurethane, etc.) [86], (ii) dispersion of finely divided silica aerogels in organic sols (which have previously proven to lead to intrinsically low conductivities [87]) and (iii) polymeric binding of superinsulating silica granules (for example, with poly-tretrafluoroethylene (PTFE) [88] or epoxides [89]). All these types of composites can have extremely low effective thermal conductivities under ambient conditions.

Among the various hybridization approaches performed with the primary goal to reinforce the tenuous solid skeleton of silica aerogels by an organic chemical modification without degrading the superinsulating property, we shall begin with the Ormosil (short for organically modified silica) methodology. The primary works of Mackenzie [90] have been significantly improved towards superinsulation applications, for example via the use of specific trialkoxysilyl [91] or polymethacrylate [92] derivatization agents. Conductivities as low as $0.015 \mathrm{Wm}^{-1} \mathrm{~K}^{-1}$ have been obtained after supercritical $\mathrm{CO}_{2}$ drying. Besides, some recent sol-gel studies performed with methylsilsesquioxane, assisted with surfactants (CTAB and poly-ethylene glycol) and urea, have permitted to obtain large monoliths with a typical bulk density of $0.10 \mathrm{~g} \mathrm{~cm}^{-3}$ through ambient pressure drying [93]. This could also represent a promising way to elaborate large superinsulating plates via a subcritical Ormosil process. Parallel to these promising studies, some cross-linking methods have recently been adapted for use in the aerospace/aeronautic thermal insulation field. They consist in reacting the remaining silanols present at the surface of the pores of silica aerogels with reactive molecules such as isocyanate and/or amines so that the fragile skeleton's inner surfaces end up coated with an organic layer [94, 95]. For the 
moment, such a technique has demonstrated its efficiency through drastically superior mechanical properties such as stress at failure and flexural modulus, however generally the density of this type of material also increases significantly. Some recent works have demonstrated it is clearly possible to decrease this dramatic densification. For example, using several bis-alkyl silanes together with polymer reinforcement by epoxy has permitted to reach minimum density of $0.2 \mathrm{gcm}^{-3}$ [96]. Some hybrid cogelation works have also been performed with modified alkoxysilanes comprising either at least one isocyanate group or, in an alternative approach, at least one amine group [97]. The so-promoted urea cross-linking permits to improve significantly the initial mechanics of the silica aerogel while maintaining thermal conductivity as low as $0.013 \mathrm{Wm}^{-1} \mathrm{~K}^{-1}$ at room temperature. Anyway, it must be underlined here that the huge majority of these brand new promising materials are processed through supercritical drying paths. Rare are the studies published on elaboration of such hybrid silica-based materials through ambient drying [98]. Recent attempt in this direction has shown that a density lower than $0.4 \mathrm{~g} \mathrm{~cm}^{-3}$ can be obtained through evaporative drying of polymer-crosslinked amine-modified wet gels [99]. This type of work lets one think that superinsulating hybrid or composite silica-based ambigels are not too distant from being accessible at the laboratory scale.

Organic aerogels have not yet been developed or at least not adapted at an industrial scale for insulation purposes but are typically used as carbon aerogel precursors [100]). Because parallel studies have shown that some of them (e.g. Resorcinol-Formaldehyde aerogels) could yield very low thermal conductivity values [101] combined with mechanical properties superior to silica aerogels [102] and thus a significantly smaller tendency of dust release, a number of more recent studies have directly targeted their insulation application. Among these works, in the late nineties, some remarkable studies were centered on polyisocyanurate aerogels [103]. The first results were excellent [104] but later studies have led to thermal conductivities above $0.020 \mathrm{Wm}^{-1} \mathrm{~K}^{-1}$ [105] partly because of micro-phase-segregation issues (Fig. 16).

Since then, this system has been intensively studied. By introducing for example polyamines in the sol together with polyol hardeners, some polyurea aerogels offering conductivities as low as $0.013 \mathrm{Wm}^{-1} \mathrm{~K}^{-1}$ at ambient conditions have recently been obtained [106]. Among the few other works initiated during this period on organic aerogel-like materials for thermal insulation, a number of studies performed on the melamine-formaldehyde system are worth mentioning. Through a microemulsion templating sol-gel route [107], some thermal conductivities slightly below $0.025 \mathrm{Wm}^{-1} \mathrm{~K}^{-1}$ have been obtained [108].

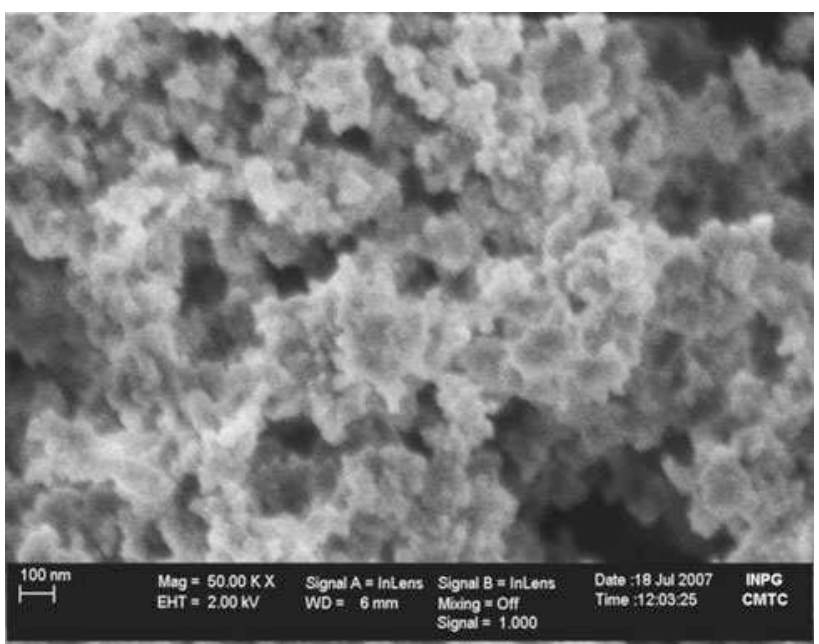

Fig. 16 Scanning Electron Microscopy of a polyurethane aerogel (SEM-FEG microscopy from F. Charlot, INPG-CMTC, Grenoble, France)

Because all these synthetic pathways use quite costly and also harmful reagents (resorcinol, formaldehyde, isocyanate, etc.) more recent endeavors in this field have been concentrating on the utilization of inexpensive and/or nonor less toxic precursors. Among the most recent studies, the work by Lee and Gould on polycyclopentadiene-based aerogels should be pointed out [109]. As a byproduct of the petrochemical industry, the monomer (dicyclopentadiene) is readily available and thus rather inexpensive. A sol-gel synthesis with this precursor can be conducted in alcohols according to a quite simple ring opening metathesis polymerization process which is catalysed by transition metal complexes of Ruthenium. The corresponding aerogels can present effective thermal conductivities lower than 0.015 $\mathrm{Wm}^{-1} \mathrm{~K}^{-1}$ at room temperature. They consequently appear extremely promising for thermal insulation applications but one must note here that, whatever the organic sol-gel synthetic method, no subcritically dried superinsulating organic aerogels are currently available even at the laboratory scale.

In parallel, recent progress in nanostructured sol-gel cellulosic materials reveals a significant potential of this type of brand new green aerogels for thermal insulation product applications.

\subsection{Commercial products}

With a large number of synthetic methods available to fabricate superinsulating aerogels let us now focus on products which are available commercially today. Those are almost exclusively based on silica. The first commercial aerogels were based on $\mathrm{SiO}_{2}$, following a recipe similar to Kistler's original procedure and were produced after 
1940 by the Monsanto Chemical Corp., Everett, Massachussetts, USA. Production stopped in the sixties for more or less two decades but started again in the early eighties (Thermalux L.P., Airglass A.B. [110]) and during the nineties (BASF [111], Hoechst[112]). Different types of aerogels were then produced for various applications (silica aerogels for the agricultural sector [113] and paints [114], carbon aerogels for energy storage and conversion devices, etc.) but a large-scale commercial adaptation by the thermal insulation trade took place only recently. At present, the two main players involved in this field are the North American industrials Cabot Corporation [115] and Aspen Aerogels [116]. They both sell silica-based aerogel products which are available in the form of a granular material or flexible blankets. Cabot Corporation has developed a family of silica aerogels under the trade name of Nanogel ${ }^{\mathrm{TM}}$ which is now being sold under the trade name Lumira ${ }^{\mathrm{TM}}$, while Aspen Aerogels is focussing on flexible aerogel blankets. Lumir$\mathrm{a}^{\mathrm{TM}}$ materials are obtained after subcritical or supercritical drying of sylilated gels synthesized from silicic acid (waterglass based). Aspen Aerogels blanket products are obtained by supercritical $\mathrm{CO}_{2}$ drying of gels generally made from alkoxysilanes. More recent competitors such as Nano Hi-Tech in China [117] and EM-Power [118] in Korea are also supplying sol-gel based superinsulating materials, however their production volume at present does not compare with the ones of the main players Cabot and Aspen. In addition there are a number of specialty aerogels companies with extremely small sale volumes. One example is Airglass $\mathrm{AB}$ (Sweden) which can supply large monolithic flat plates of silica aerogel. These monoliths have been designed and developed initially for very specific scientific applications such as elementary particle physics counters at CERN, Geneva, Switzerland, however in a later stage their properties were optimized for applications in supersinsulating glazings, so-called aerogel glazings. Due to the tremendous production effort required to manufacture such monoliths defect free, this particular application will most likely not become industrially competitive in the near future.

Additional developments are going on worldwide to develop improved insulating components and systems based on current silica aerogel technology, both at the materials and component levels. As far as application is concerned, Nanogel ${ }^{\mathrm{TM}}$ granules can be directly used as superinsulating filling materials (such as for example, in daylighting panels) but CABOT is also marketing Nanogel $^{\mathrm{TM}}$-based components (such as Thermal Wrap ${ }^{\mathrm{TM}}$ and Compression Pack ${ }^{\mathrm{TM}}$ ) for specific applications like pipe-in pipe and cryogenic insulation systems. For its part, Aspen is commercializing blanket-based components for building insulation (so-called Spaceloft) as well as materials optimized for use in extremely hot and cold environments (Pyrogel and Cryogel products).

\section{Applications}

\subsection{Overview}

The role of superinsulation as niche products in the insulation business and their particular importance for space saving applications has been presented previously. A lower thermal conductivity means that the same insulation performance is achieved with a thinner insulation layer, or, that the same thickness of superinsulation is used to ensure far better insulation performance. This advantage is contrasted by a significantly higher cost per installed performance as shown below. This assessment is based on data from 2009 .

In order for a high priced superinsulation product to become competitive with conventional ones, the value of the "saved space" and other beneficial factors must compensate significantly for the added cost of the material. In this context the key question to be addressed is: how can one put a dollar value on space savings? Depending on the type of application, a reduction in space, weight or volume affects overall assembly and operation cost (Fig. 17). The aerogel insulation business must find small niche markets to set foot in, which are best evaluated according to their potential for capitalizing on their benefits. Such niche markets can later serve as a basis for expanding activities into other fields of business. Table 2 shown below gives an overview of today's typical aerogel insulation applications and their economic relevance.

For most aerogel insulation products, the reduction of the operating cost is higher than the savings accrued during installation. However in the case of off-shore oil and gas pipeline insulation, the installation part is the key factor in favor of aerogel-based products: With significantly smaller pipe diameters and reduced weight, assembly ships can carry significantly more pipeline with each trip, thus significantly cutting down on the number of trips and the overall installation cost. This is a model example of how an extremely specialized application can open up opportunities for high-performance high-cost products. In the

\begin{tabular}{|c|c|c|c|}
\hline & Aerogel & $\begin{array}{l}\text { Vacuum } \\
\text { Insulation } \\
\text { Panels (VIP) }\end{array}$ & $\begin{array}{l}\text { Conventional } \\
\text { Insulation }\end{array}$ \\
\hline $\begin{array}{l}\text { Thickness } \\
\text { for } U=0.2 \\
W m^{-2} K^{-1}\end{array}$ & $\begin{array}{l}7.5 \mathrm{~cm} \\
\lambda=0.015\end{array}$ & $\begin{array}{c}4 \mathrm{~cm} \\
\lambda=0.08\end{array}$ & $\begin{array}{l}16 \mathrm{~cm} \\
\lambda=0.032\end{array}$ \\
\hline $\begin{array}{l}\text { Materials } \\
\text { cost }\end{array}$ & 280 US\$ $\mathrm{m}^{-2}$ & 220 US $\$ m^{-2}$ & 15 US $\$ \mathrm{~m}^{-2}$ \\
\hline
\end{tabular}

Fig. 17 Comparison of space savings and cost of conventional insulation, aerogel and vacuum insulation systems. Units of the thermal conductivity $\lambda$ are in $\mathrm{Wm}^{-1} \mathrm{~K}^{-1}$ 
Table 2 Typical aerogel insulation product branches, their space savings benefit and economic relevance

\begin{tabular}{|c|c|c|c|}
\hline Application: & Installation and assembly cost & Operating cost & $\begin{array}{l}\text { Economic } \\
\text { potential }\end{array}$ \\
\hline Off-shore oil and gas & $\begin{array}{l}\text { Smaller pipe diameter, lower weight, more pipes } \\
\text { per installation round trip, fewer trips }\end{array}$ & Superior lifetime, improved degradation resistance & ++++ \\
\hline Aeronautics/aerospace & $\begin{array}{l}\text { Simplification of overall design, light } \\
\text { construction, size reduction lowers materials/ } \\
\text { assembly cost }\end{array}$ & $\begin{array}{l}\text { Smaller gross weight results in results in fuel } \\
\text { savings or additional capacity }\end{array}$ & $++(+)$ \\
\hline Building insulation & $\begin{array}{l}\text { Comparable to conventional insulation, currently } \\
\text { more elaborate due to lack of experience }\end{array}$ & $\begin{array}{l}\text { Reduction of heating/cooling energy and/or larger } \\
\text { useable building/exterior volume }\end{array}$ & $+++(++)$ \\
\hline $\begin{array}{l}\text { High temperature } \\
\text { insulation }\end{array}$ & $\begin{array}{l}\text { Smaller overall pipe diameter or exterior } \\
\text { dimensions, easier installation }\end{array}$ & $\begin{array}{l}\text { Reduced surface area per unit length, lower } \\
\text { radiative losses, improved resistance and lifetime }\end{array}$ & +++ \\
\hline Cryogenic applications & $\begin{array}{l}\text { Smaller overall pipe diameter or exterior } \\
\text { dimensions, easier installation }\end{array}$ & $\begin{array}{l}\text { Reduced sensitivity to cryo-embrittlement, } \\
\text { increased lifetime, energy and/or space savings }\end{array}$ & ++ \\
\hline Appliances and apparel & $\begin{array}{l}\text { Significantly more complex than standard } \\
\text { technology }\end{array}$ & $\begin{array}{l}\text { Energy savings/increased thermal comfort for } \\
\text { lightweight extreme performance personal wear/ } \\
\text { gear }\end{array}$ & ++ \\
\hline
\end{tabular}

following we shall briefly discuss the various types of aerogel insulation products which are available commercially today. Of course, it must be preliminary said that all current commercial products are silica-based.

\subsubsection{Off-shore oil and gas}

This is one of the oldest fields of activity of the Aspen Aerogels Spaceloft thermal insulation blanket. Cabot Corporation is offering their Nanogel-filled Compression Pack as a promising alternative solution to the blanket product. The superior thermal performance and improved chemical/pressure resistance of aerogels combined with assembly cost savings make them ideal candidates for this type of application. To this day, this is the undisputed model example for finding a niche market for aerogel insulation products and exploring it successfully.

\subsubsection{Aeronautics and aerospace applications}

One of the traditional fields of aerogels during their revival in the 1960s following Kistler's discovery in 1925, the materials was extensively studied by the US space administration NASA. Large monolithic aerogel blocks are being used to collect stellar dust and particles in outer space (, on the Mars Rover roving vehicle silica aerogels were used for thermal insulation. Given their space savings potential and relatively low weight, aerogel insulation systems could also find applications in civil and military aviation, however little activity is known in this field so far, most likely for cost reasons.

\subsubsection{High temperature}

There are a number of industrial processes which require pumping hot fluids from one place to another. Many older plants were designed and built with little or no insulation, especially at times where energy was all abundant and cheap. These days, significant savings can be generated by insulating the piping systems of steam cycles, chemical processes or oil and gas processing refineries. This opens up a large potential for high performance insulation systems, particularly for older or already existing plants with restricted access and tightly spaced arrangements of individual pipes. Aspen's Pyrogel is a product which was developed especially for high-temperature applications.

\subsubsection{Cryogenic applications}

In the field of cryotechnology, which includes for example transport and storage of liquefied gases or frozen biomedical specimens, aerogel insulation offers numerous advantages. Besides its superinsulation properties, aerogels tend to embrittle less with decreasing temperature than for example polymer foam insulation. Aspen Aerogels have developed a special low-temperature aerogel blanket insulation product, the Cryogel Z. Granular products such as Cabot's Nanogel offer great versatility for lining nontrivial vessel and piping geometries which are part of more complex cryogenic systems. Cryogenic aerogel insulation is also investigated by the NASA's rocket engine research teams for liquid hydrogen and liquid oxygen propelled drive systems [119].

\subsubsection{Apparel and appliances (refrigeration systems, outdoor clothing \& shoes)}

Superinsulation properties can find use in a number of everyday products. Particularly personal apparel such as performance outdoors equipment for example clothing, shoes, gloves, foot warmers, tents, sleeping bags etc. could 
be outfitted with aerogel thermal insulating layers. The same holds for household appliances such as refrigerators or outdoors cooling boxes. A number of such products have recently reached consumer markets. With increasing market volume and increasing customer awareness, such products have a significant potential to compete in the high-priced products sector. However it is unlikely that aerogel based consumer products will conquer the middle and low-cost sectors.

\subsection{Zoom on building insulation}

At the beginning of this chapter the need for superinsulation was founded on the imminent necessity for a global $\mathrm{CO}_{2}$ reduction. It was shown that insulating the existing building stock can bring about substantial energy savings and that it is amongst the most sensible short-term measures to curb $\mathrm{CO}_{2}$ emissions quickly. Given the tremendous volume of insulation materials needed for building applications, this is clearly one of the fields with a huge potential for the worlds growing areogel insulation markets.

With emphasis on retrofit where space saving is key, the main applications of aerogel materials in the building industry are:

- renovation of historical buildings (exterior insulation)

- interior insulation and transparent/translucent daylighting and windows

- flat-roof balcony constructions (aerogels as a less damage sensitive alternative to VIP)

- Aestethic architecture with slim exterior insulation, light weight elements

The bulk of newly constructed buildings and most renovations will still go on using conventional insulation products, because the extra space gained by a slimmer insulation only compensates the added cost in high-prized locations (inner city). This is the main reason why aerogels have only very hesitantly found their way into the building insulation sector, nevertheless, this trend is currently changing with more and more new aerogel based insulation products and demonstration projects appearing these days.

\subsubsection{Monolithic aerogel windows}

One of the holy grails of building technology is the practical realization of highly insulating windows to achieve U-values comparable to those of façade insulation. In this context, it needs to be mentioned that the standards of window elements worldwide is extremely poor compared to the state of the art. In Central and Northern Europe most new windows are double paned with low-e coating and noble gas fillings, reaching typical U-values around 1.0
$\mathrm{Wm}^{-2} \mathrm{~K}^{-1}$. However even today in large parts of the civilized world for example in North America (the United States and Canada) but also in Asia, more than $40 \%$ of new windows are single-paned with a $U$ value of $\sim 6.0$ $\left.\mathrm{Wm}^{-2} \mathrm{~K}^{-1}\right)$ ! With barely airtight sash and frame constructions, in North America alone each year roughly 400 billion $\mathrm{kWh}$ are wasted in this way, losses which could be eliminated if double glazed systems were to be put in place. Nevertheless, with building codes and regulations tightening, a need for further improvement of double paned windows to reach $\mathrm{U}$-values below $0.5 \mathrm{Wm}^{-2} \mathrm{~K}^{-1}$ are essential. As an alternative to vacuum glazing, aerogel filled double paned windows (also partially evacuated) have been considered for decades as a promising alternative to gas filled panes. Airglass A.B. in Sweden was one of the first entrepreneurs in this very exciting field. The adventure began during the 1980's in the neighborhood of Lund with TMOS as the silica precursor [120]. The original material has steadily improved since this time, especially working on the basis of a sol-gel route using polyethoxydisiloxane from PCAS [121]. At the end of the HILIT/ HILIT + projects funded by the European Commission, Airglass $\mathrm{AB}$ was able to prepare in batch some $1.5 \mathrm{~cm}-$ thick $55 \times 55 \mathrm{~cm}^{2}$, monolithic, crack-free and flat, aerogel plates presenting an excellent thermo-optical compromise : a low thermal conductivity $(\sim 17 \mathrm{~mW} / \mathrm{m} . \mathrm{K}$ under ambient conditions) together with a rather high transparency ratio $(\mathrm{TR} \sim 90 \%)$ and a very low extinction coefficient $(\mathrm{E}<10$ $\mathrm{m}^{-1}$ ) [122]. The associated aerogel-glazing prototypes shown in Fig. 18, elaborated by DTU (Denmark) under primary vacuum with two low-iron glass layers and a lowconductive rim seal solution, presented a centre U-value lower than $0.7 \mathrm{~W} / \mathrm{m}^{2} . \mathrm{K}$ and a solar transmittance close to $75 \%$ [59]. Amongst other, it has been demonstrated that the use of such brand new glazed components in new buildings could permit to increase the north facing glazing area even, in some cases, with energy gain. Unfortunately, the processing of these high-tech silica aerogel plates appears rather difficult and the plates themselves remain mechanically weak.

More recently, Aspen Aerogels has engaged in the development of reinforced but highly translucent, monolithic aerogel panels for "aerogel window" applications. The technology is currently still under development, however the fact that one of the major players in the aerogel business is involved in this type of activity raises hope that a commercial solution may be within reach. But what about the cost? In Europe, the going rate for a standard triple glazed window is around $800 \$$ per square meter. A $2.5 \mathrm{~cm}$ thick monolithic aerogel plate sandwiched in between two glass panes could reach a U-value below $0.5 \mathrm{Wm}^{-2} \mathrm{~K}^{-1}$. The difficulty is to produce monoliths of high optical quality (no defects, cracks, inhomogeneities) 


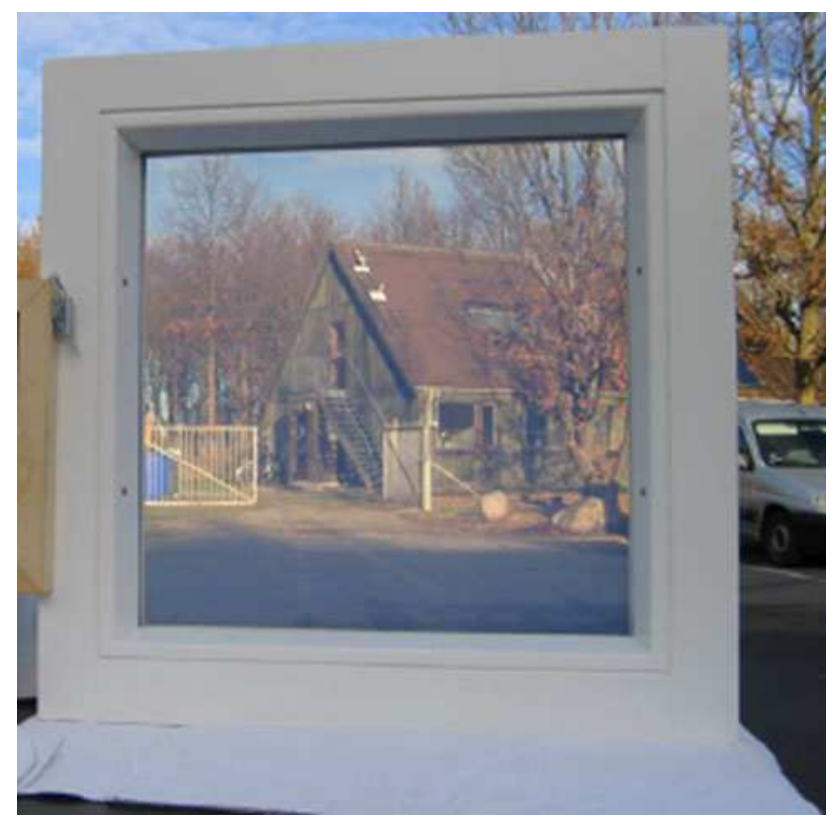

Fig. 18 Example of super-insulating aerogel glazings developed within the frame of the HILIT + European project based on the use of silica aerogels plates from AIRGLASS AB (inspired from [122])

in the form of perfect plates of at least $0.5 \mathrm{~m}$ by $0.5 \mathrm{~m}$ dimension. If we use a bulk volume price of silica aerogel of $4,000 \$$ per $\mathrm{m}^{3}$, the additional cost originating from the aerogel itself of around $100 \$$ per $\mathrm{m}^{2}$ could be attractive. However, high optical quality, large area monolith are most likely going to come with a significantly higher price tag due to the more delicate handling and processing steps and perhaps also a non-negligible reject rate. From a market perspective, a lighter double paned aerogel monolith glazing offers great promise. So far, the slow processing due to the extremely delicate nature of the gels as well as their supercritical drying process have rendered any attempts for commercialization unsuccessful.

\subsubsection{Transparent daylighting applications}

Granular translucent aerogel materials are much easier to handle, as they can be poured like a powder. The first and largest industrial supplier of high optical quality granular silica aerogels is Cabot. Their Nanogel ${ }^{\circledR}$ (now Lumira) products have been at the forefront of transparent daylighting applications. By filling a transparent cavity or profile, highly insulating modules or windows can be produced which still allows for a high transmission of diffusely scattered light. The main difference to a monolithic aerogel plate is that the granular material no longer remains optically transparent, and thus no longer allows to recreate an optical image, as if viewed through a milk glass. Due to the numerous air/aerogel interfaces, a packed bed of aerogel granules scatters light much more which results in exactly this type of translucent properties. Diffuse lighting offers the advantage of a softer light and reduced shadowing and glare when compared to a standard window.

Scobalit [123] is a pioneer in aerogel filled composite panels for translucent daylighting applications. Their superinsulating Scobatherm product consists of an aerogel granulate filled glass fiber reinforced polyester resin composite profile. One of its first uses in a building for daylighting is the roof construction of the School "Buchwiesen" shown below in Fig. 19 which was designed by V. and A. Amsler architects and constructed by the City of Zürich in 2003.

Another type of transparent daylighting solution for roof constructions are the use of textile roof elements. In North America, Birdair [124] is a pioneer in the construction of suspended, tent-like aerogel roofing solutions. To date a number of different applications for these lightweight textile roofing systems with superior insulation performance have been realized covering industrial buildings, event halls, convention centers, hotels and sports complexes. One of the better known examples today is the retrofit of the roughly $5,000 \mathrm{~m}^{2}$ large Dedmon Athletic Center of Radford University in Radford, VA, USA. The use of Birdair's Tensotherm system resulted in a reduction of the total heating and cooling energy demand by roughly three quarters. At the moment, a much larger sports facility, the Talisman Centre in Calgary, Canada, is being retrofitted which spans an area more than three times that of the Dedmon Athletic Center. Transparent textile roofing is in fact an excellent example for the overall economic efficiency of aerogel solutions, which despite the high materials costs are offset by their low weight, simple installation, longevity, optical transmission and water vapor permeability. All these factors combined make Tensotherm a highly competitive product for large and heated/cooled spaces.

Last but not least, granular silica aerogel can also be used to fill the cavity in a double glazing, resulting in an opaque but highly insulating window element. The German company Okalux [125] has developed an aerogel filled

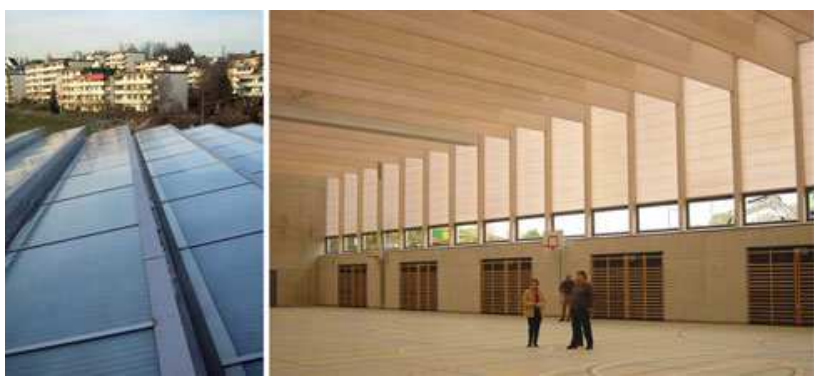

Fig. 19 First example of the use of Cabot aerogel granulate filled Scobatherm glass fiber composite panels in the form of a transparent daylighting roof construction is the gymnastics and physical education hall of the school Buchwiesen in Zurich which was constructed in 2003 
window termed Okagel which offers thermal transmittance values down to $\mathrm{U}=0.3 \mathrm{Wm}^{-2} \mathrm{~K}^{-1}$. Their most famous demonstrator unit to date is the window elements used in the British Haley VI Research Station in the Antarctic. In less adverse climatic conditions, the Tengelmann Climatic Market in Mühlheim, Germany, was outfitted with Okagel roof window elements. Aerogel filled windows offer an additional quite substantial thermal performance advantage over standard window elements when installed in a nonvertical fashion. For tilted and flat-roof standard windows, the certified U-values can no longer be upheld, because of a substantial increase in the convective heat transfer of the filler gas which is suppressed under normal vertical installation conditions. In an aerogel filled window, convective heat transfer does not notably contribute to the overall thermal performance.

\subsubsection{Other aerogel granulate based insulation}

Aside from their use in translucent daylighting, granular silica aerogels are also employed in other forms as highperformance insulation. The simplest example is the retrofitting of cavity walls. In this type of application, packed bed of plain aerogel is directly injected as filler into a cavity wall construction without additional modifications. The excellent flow properties of silica aerogel granules allow for a quick and efficient filling through small bore holes of typically $30-50 \mathrm{~mm}$ diameter. A recent example of such a retrofit is shown in Fig. 20. After the retrofitting, the U-value of the $9 \mathrm{~cm}$ cavity wall construction dropped from 1.1 to $0.18 \mathrm{Wm}^{-2} \mathrm{~K}^{-1}$, that is to less than one-fifth of its initial value, which is below the strict Swiss building standards of 2012 for new construction objects.

\subsubsection{Composite building materials and products based on aerogel granulate and powders}

More recently, a number of building material manufacturers have realized the importance of aerogel insulation

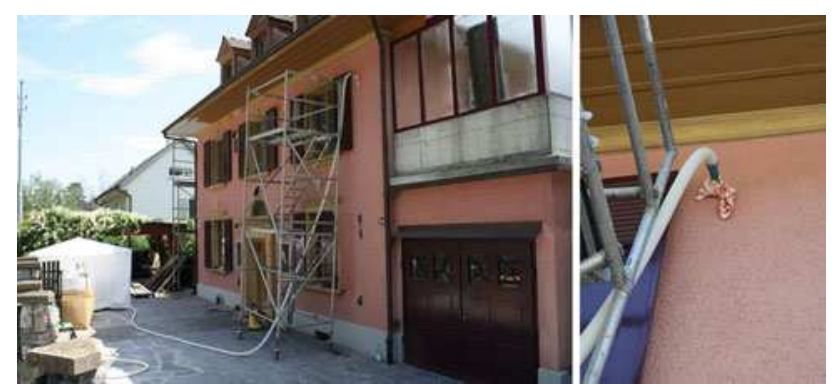

Fig. 20 Cavity wall insulation with aerogel granulate in Biel, Switzerland. View of the renovation site (left) and zoom on the injection hole (right) due to their excellent overall properties and thus a number of silica aerogel granulates based composites have been developed. In 2010 the mineral wool fiber producer Rockwool [126] has announced their Aerowool product [127], board/like product made by compounding aerogel granulates with mineral wool and resin based binders. In this way, a sturdy, lightweight insulation board with a thermal conductivity around $0.020 \mathrm{Wm}^{-1} \mathrm{~K}^{-1}$ is produced.

Another highly promising application of granular silica aerogels is in high performance insulating plaster and rendering systems. One such system was recently developed [128] at the Swiss Federal Institute for materials Science and Technology, Empa, together with the Fixit group [129]. The render contains more than $80 \%$ silica aerogel granulate in volume and can be sprayed and applied on walls with conventional industrial machinebased projection systems. Figure 21 shows an image of a test wall, from which later on test samples were cut out and thermal conductivity values $\lambda$ below $0.025 \mathrm{Wm}^{-1} \mathrm{~K}^{-1}$ were measured. This represents more than doubling of the thermal insulation performance of standard insulating plaster materials which typically offer thermal conductivities around $0.08-0.09 \mathrm{Wm}^{-1} \mathrm{~K}^{-1}$ under ambient conditions when measured from specimens that were cut from a wall spray test.

The French mortar and plaster based products producer Parexlanko [130] together with MINES ParisTech/ARMINES/CEP have followed a rather different approach. Instead of minimizing the lambda value by adding "the" highest possible volume fraction of granular hydrophobic silica aerogel, their goal was to target a satisfactory thermo-mechanical compromise regarding the application for external thermal insulation, using methods as close as possible to traditional ones (i.e. cement based mortars, traditional projection technique) [131]. Some mortars) with thermal conductivity values close to $0.050 \mathrm{Wm}^{-1} \mathrm{~K}^{-1}$ (as measured with the hot-guarded plate method) together with flexural strength larger than 0.5 $\mathrm{MPa}$ were produced at preindustrial level and are currently tested on new experimental and old existing buildings within the frame of a French FUI (Fonds Unique Interministériel) project (Fig. 22).

The compounding of granular aerogels today has penetrated virtually all types of construction materials. Much in the same way as the render and mortar products, Ratke [132] demonstrated proof of concept of ultralightweight concrete by mixing sand, cement and up to $70 \%$ of silica aerogel granulate by volume. This astonishing material offers still excellent mechanical strength and thermal conductivity values as low as $0.1 \mathrm{Wm}^{-1} \mathrm{~K}^{-1}$, making it a perfect candidate for extreme fire resistant concrete construction. 

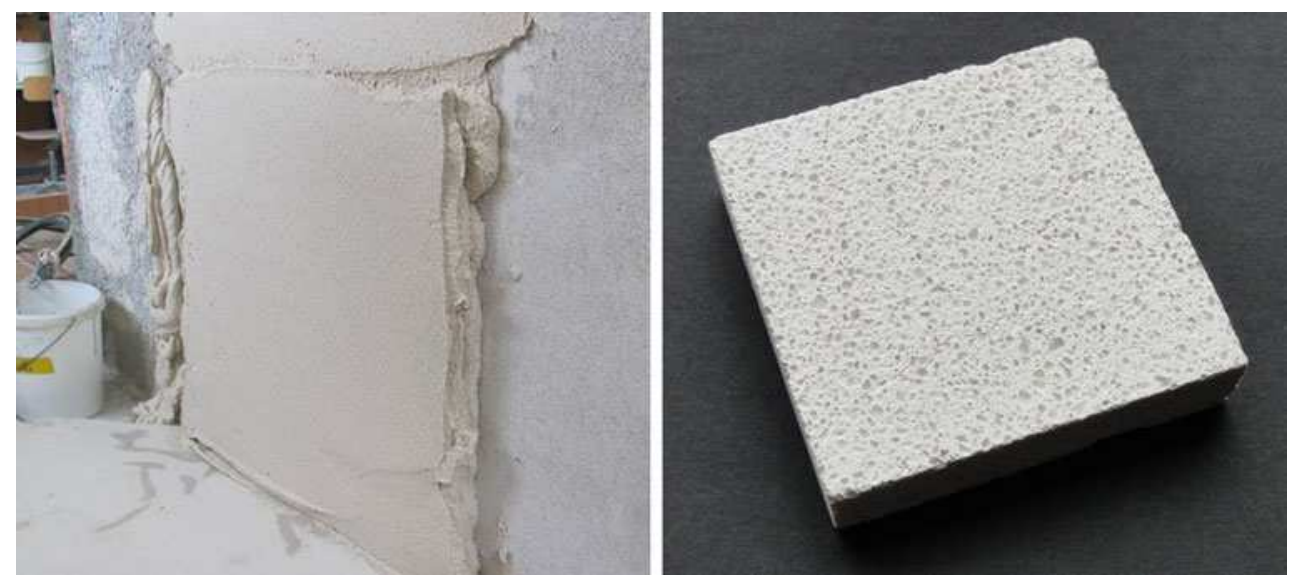

Fig. 21 High-performance insulating render system developed by Empa and Fixit. Wall spray test (left) and cut cross section of the material clearly showing individual aerogel granules (right)
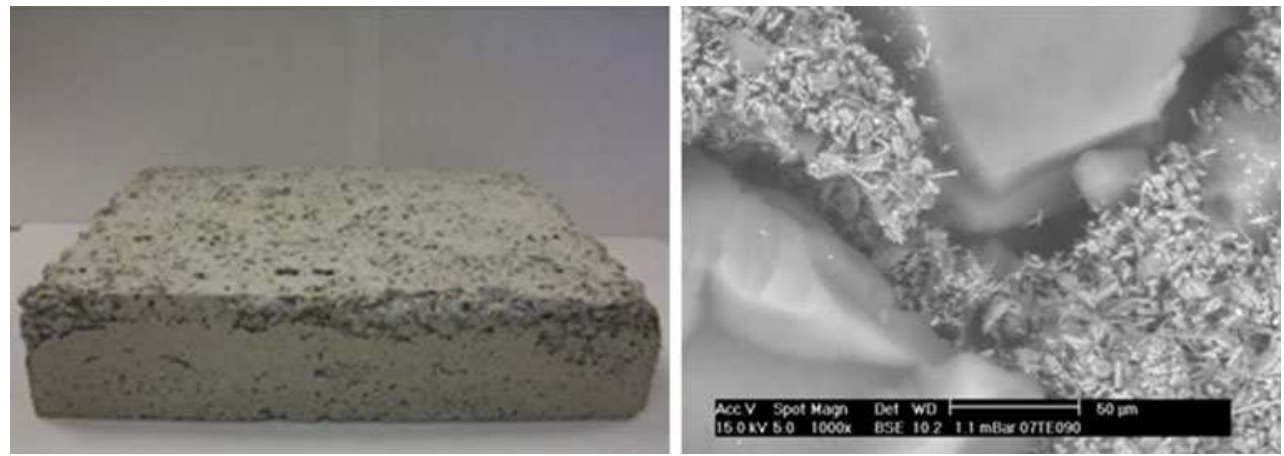

Fig. 22 View of a representative superinsulating silica xerogel-based mortar sample developed by Parexlanko and Armines (left) and the corresponding micrograph (right)

\subsubsection{Aerogel infused blanket products and derivatives}

The largest producer of aerogel materials today by volume is Aspen Aerogel. Their main product is a polymer blanket silica aerogel composite which is obtained by wet gel impregnation and supercritical $\mathrm{CO}_{2}$ drying. Their standard product for ambient temperature application, the Spaceloft blanket, also finds more and more widespread use in the building industry. The retrofitting of old buildings, where the exterior appearance must be maintained, often requires extremely thin insulating layers. In the form of a demonstration project supported by the Swiss federal office of energy (BFE), a multifamily home in Zurich was retrofitted with Aspen Spaceloft blanket insulation, allowing the object to maintain its original style and form (Fig. 23).

The original wall was stripped of its rendering and two $10 \mathrm{~mm}$ thick Spaceloft mats were glued on. Then a standard insulating rendering of $30 \mathrm{~mm}$ thickness was applied. The so obtained U-value of the retrofitted wall element was below $0.4 \mathrm{Wm}^{-2} \mathrm{~K}^{-1}$ or less than one-third of the original value. Figure 24 shows two images of the renovation work, including the installation of Spaceloft blankets. Due to the dust evolution of the blankets during cutting and handling, the workers are required to wear protective safety gear.

In an attempt to simplify the installation of aerogel blanket products, the German construction material manufacturers Röfix [133] and STO [134] have developed their own aerogel based sandwich composite boards. The Röfix product AEROCALCE is an Aspen Aerogel Spaceloft composite with an attached adhesion and lime mortar layer. The STO "in Aevero" product is a similar composite board but made from granular aerogel by compounding with polymeric binders. Both products target the building retrofit industry with the added benefit of greatly facilitated installation. AEROCALCE was used also for insulating the basement of the cavity wall retrofit object in Biel, Switzerland, shown earlier in Fig. 20. Details of the basement level insulation with this product are shown below in Fig. 25.

Together with a number of other central and northern European countries, Germany, Austria and Switzerland have taken a leading role in energy and environment related issues. Supported by their government's trend-setting energy policy, innovation in the field of energy 


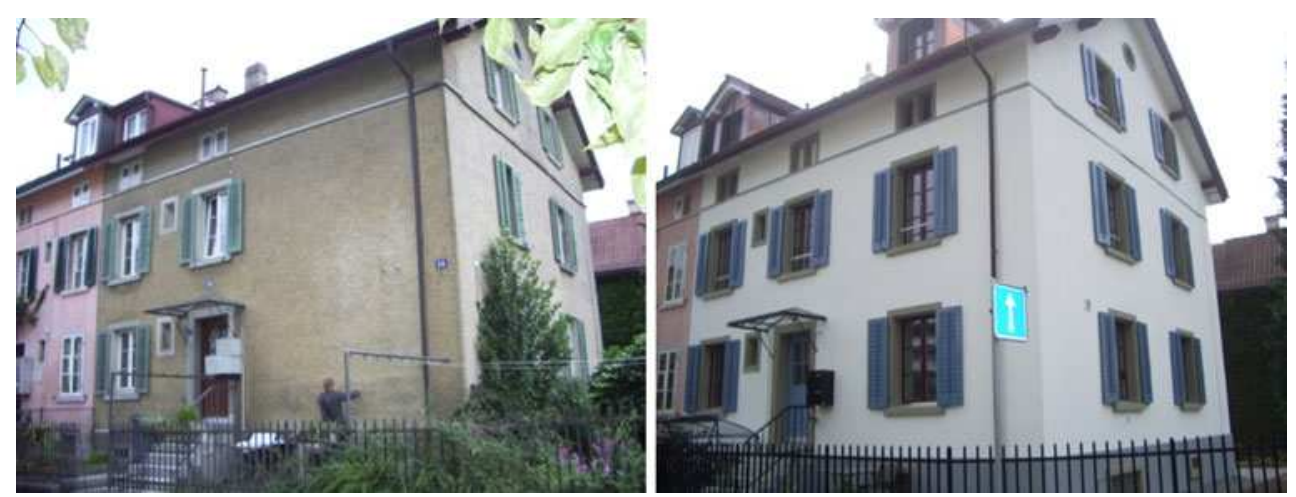

Fig. 23 Retrofit of an early 20th century city multifamily house in Zurich, Switzerland. Exterior appearance before (left) and after (right) the renovation
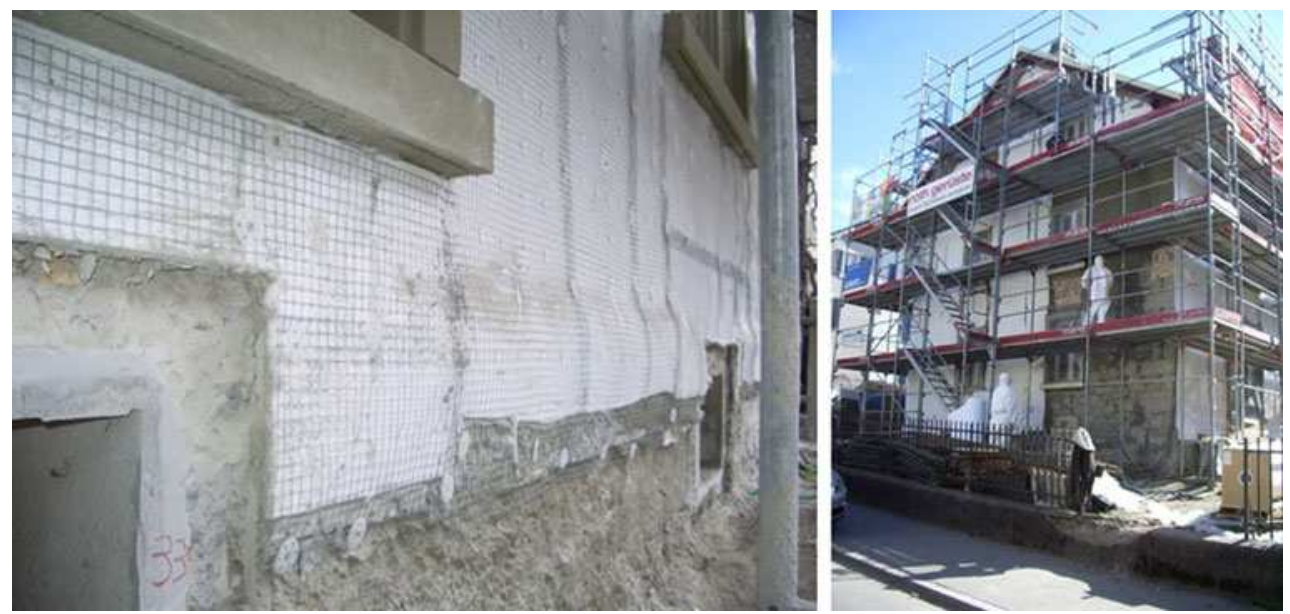

Fig. 24 Retrofit wall insulation with Spaceloft blankets. Wall and window sill detail (left) and house side-on view (right)
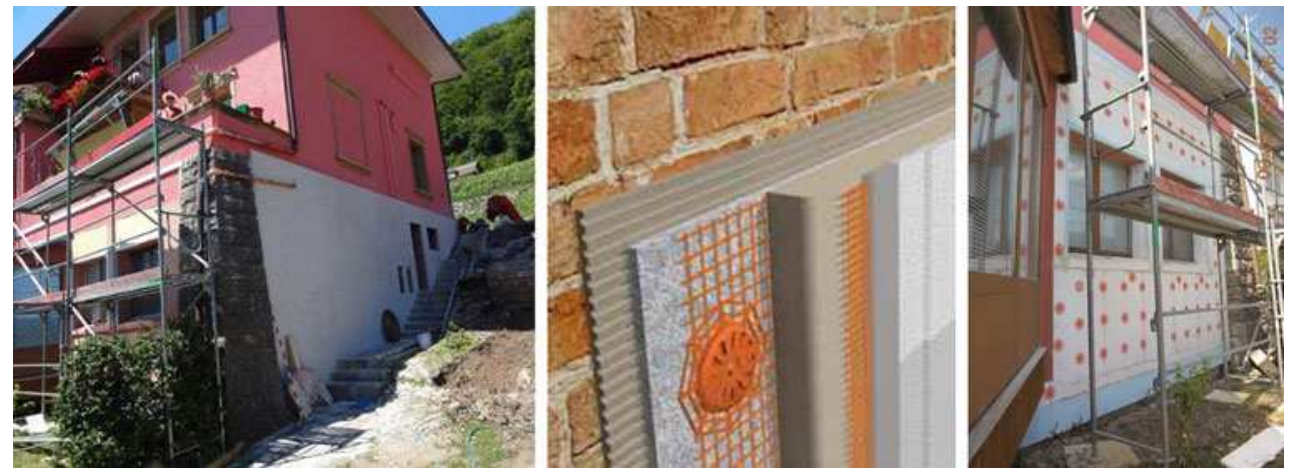

Fig. 25 Retrofit basement level insulation with Röfix AEROCALCE aerogel blanket insulation system. Building front/side-on view (left), cross section of the layered nature of the AEROCALCE system (middle) as well as ground level wall and window details (right)

efficient building and construction have been subsidized and promoted in recent years. This has allowed for new, high-priced high-performance products and solutions to make their way into selected demonstration units which are often funded in part by the government. Even though a lot has happened within the past 5 years in the field of aerogel based insulation systems and components, aerogel superinsulation is still not ready for a broad application in the building market yet, mostly because of its price. Nevertheless, the speed and intensity of new developments precipitating onto the building market indicates that there is still plenty of room for innovation of aerogel superinsulation products in the not too distant future. With increasing market volume and falling aerogel prices, the saved space 
will more and more be able to compensate the extra cost. At this point, it may also be mentioned, that aerogel based insulation offers two inherent advantages over the most commonly used polymer foams, namely that it is both nonflammable and water vapor open. Even though almost forgotten over the past 20 years, one can observe a generally rising awareness on the side of the installers to the tight sealing of the gaps between insulation polymer foam plates (even though beneficial for optimized thermal insulation) as this situation inherently bears a substantial risk for condensation damage. Due to their open porous nature, this problem is eliminated when using aerogel based insulation. Today markets seem to indicate that aerogels are the insulation materials of the future - the question now remains to see which products are going to secure what section of the market and how quickly production volumes will rise and prices drop.

\subsection{Safetly, health and toxicity considerations}

Nanomaterials in general are currently being investigated worldwide for their potential health and environmental risks [135]. As nanostructured materials, aerogels are nanomaterials and hence need close observation. Silica aerogels, the most prominent aerogel insulation materials, are made from colloidal silica nanoparticle building blocks. Now the question arises whether there is a significant health risk for end-users and the immediate environment where the product is applied. From a risk assessment point of view, the potential danger of a new nanomaterial is given by the product of intrinsic toxicity of the nanomaterial (nanotoxicity) and risk (probability) of exposure.

The toxicity of nanoparticulate silica has been widely studied in recent years [136]. Generally amorphous silica nanoparticles are considered relatively safe, however the surface functionalization must be taken into account when assessing the specific (for example cell-) toxicity. Crystalline $\mathrm{SiO}_{2}$ nanoparticles are accompanied by a significantly higher risk for cell mutagenesis, however sol-gel processes produce amorphous materials unless they are sintered for longer periods of time at elevated temperature which can induce crystallization at the nanodomain level. From an exposure point of view, the risk of exposure to significant quantities of nanoparticulate silica when working with aerogels such as by inhalation is also quite low. Given the three dimensional network structure of aerogels, the resulting dust contains only very few individual particles in the nanometer size regime. By far more likely is the formation of chunks or fragments of the entire network in the micrometer size regime, consisting of many particles still covalently bound to each other. The dust produced in this way is in a way more similar to typical household dust.
Even though nanosafety does not seem an immediate concern for aerogel insulation, prototypes of each next generation product must be tested thoroughly. Manufacturers and businessmen alike must keep in mind the tremendous negative impact on the entire aerogels industry which can come from a single negative example. Because nanotoxicity is such a new field with a lot of unknowns, the power of bad news and their potential impact as a market inhibitor is tremendous. Therefore proper action must be taken so that the nanotoxicity problematic be addressed adequately in all instances. Of course, when more developed, organic or composite/hybrid aerogel insulators must be studied in the same way.

\section{Conclusions}

Aerogel based insulation products have established a place in various niche markets, particularly in the insulation products trade, over the past 10 years. Aerogel superinsulation affords superior insulation performance (lower thermal conductivity values) compared to conventional materials which translates into slimmer installed constructs and/or improved insulation performance. Motivated by global $\mathrm{CO}_{2}$ emission and space saving restrictions, aerogel superinsulation products will continue their advance into new market segments. The development of improved aerogel insulation systems and rapidly advancing process technology will allow manufacturers to promote next generation custom-tailored products. Inorganic (particularly $\mathrm{SiO}_{2}$ based) materials are likely to play a key role, also for years or decades to come. It is expected that in addition to the pure silica systems, organic aerogels and a variety of composites and/or hybrids (such as organicinorganic or fiber-reinforced) materials and products will become available. Overall, the aerogels insulation products have a tremendous growth potential in excess of $50 \%$ by volume per annum. For comparison conventional insulation products grow at an annual rate on the order of $5 \%$. In 2008 aerogel insulation products contributed less than $0.3 \%$ to the total insulation products market volume.

Today, the materials cost for aerogel insulation is roughly twenty times higher (per installed performance) than that of standard insulation products. The main justification for the use of aerogel insulation systems therefore is space saving, reducing operating cost, longevity, and chemical resistance. Off-shore oil, high-temperature and building insulation as well as aeronautics/aerospace applications are the industry trades with the most significant growth potential for aerogel products in terms of estimated sales volume. Of all these, the building has certainly by far the largest growth potential but is also more sensitive to the 
materials cost than for example the aeronautics/aerospace field.

A current reference market price for a cubic meter of silica aerogel is on the order of 4,000 US\$ (2008). With increasing commercialization, this value could drop below the 1,500 US\$ mark by the year 2020. Lower prices will cause an equilibration or stabilization of the aerogels insulation market. The advance of organic and hybrid/ composite systems could invigorate this development process additionally. In the meantime we shall look forward to seeing new aerogel insulation products and companies appear on the World markets.

Acknowledgments The authors would like to acknowledge Springer publishing and the main editors Michel Aegerter and Nicholas Leventis for their involvement in the Aerogels Handbook by which this review article was inspired. Also, the European Commission, the French Agency for Environment and Energy Management (ADEME), the French National Research Agency (ANR), the French „Fonds Unique Interministériel “(FUI) fund and ARMINES (The Contract Research Association of MINES Schools) for their financial support since the early nineties through different projects (like HILIT, HILIT+, PACTE Aerogels, ISOCOMP and NANO-PU), MINES ParisTech/ARMINES/CEMEF for SEM/TEM characterization support and last but not least, the industrials PCAS FIXIT/HASIT and PAREXLANKO as well as the French Scientific and Technical Centre for Building (CSTB) are warmly acknowledged for fruitful collaborations.

\section{References}

1. Barsky RB, Kilian L (2004) Oil and the macroeconomy since the 1970s. J Econ Persp 18(4):115-134

2. Woodwell GM (1978) The carbon dioxide question. Sci Am 238:34-43

3. Cox PM, Betts RA, Jones CD, Spall SA, Totterdell I (2000) Acceleration of global warming due to carbon cycle feedbacks in a coupled climate model. Nature 408:184-187

4. Houghton JT, Jenkins GJ, Ephraums JJ (1990) Climate change-the IPCC scientific assessment. Cambridge University Press, Cambridge

5. Caldeira K, Jain AK, Hoffert MI (2003) Climate sensitivity uncertainty and the need for energy without $\mathrm{CO}_{2}$ emission. Science 299(5615):2052-2054

6. Weber L (1997) Some reflections on barriers to the efficient use of energy. Energy Policy 25(10):833-835

7. Aegerter MA, Leventis N, Koebel MM (eds) (2011) Aerogels handbook. Springer, Berlin

8. Janda KB, Busch JF (1994) Worldwide status of energy standards for buildings. Energy 19(1):27-44

9. Papadopoulos AM (2005) State of the art in thermal insulation materials and aims for future developments. Energy Build 37(1):77-86

10. Lee OJ, Lee KH, Yim TJ, Kim SY, Yoo KP (2002) Determination of mesopore size of aerogels from thermal conductivity measurements. J Non-Cryst Solids 298:287-292

11. Viskanta R, Gosh RJ (1962) Heat transfer by simultaneous conduction and radiation in an absorbing medium. J Heat Trans 2:63-71

12. Scheuerpflug P, Caps R, Büttner D, Fricke J (1985) Apparent thermal conductivity of evacuated $\mathrm{SiO}_{2}$ aerogel tiles under variations of radiative boundary conditions. Int $\mathrm{J}$ Heat Mass Transf 28:2299-2306

13. Bernasconi A, Sleator T, Posselt D, Kjems JK, Ott HR (1992) Dynamic properties of silica aerogels as deduced from specificheat and thermal-conductivity measurements. Phys Rev B 45:10363-10376

14. Vacher R, Woignier T, Pelous J (1988) Structure and self-similarity of silica aerogels. Phys Rev B 37:6500-6503

15. Craievich A, Aegerter MA, dos Santos DI, Woignier T, Zarzycki J (1986) A SAXS study of silica aerogels. J Non-Cryst Solids $86: 394-406$

16. Hasmy A, Foret M, Anglaret E, Pelous J, Vacher R, Jullien R (1995) Small-angle neutron scattering of aerogels: simulations and experiments. J Non-Cryst Solids 186:118-130

17. Simmler H, Brunner S (2005) Aging and service life of VIP in buildings. Energy Build 37(11):1122-1131

18. Manz H (2008) On minimizing heat transport in architectural glazing. Renewable Energy 33(1):119-128

19. Koebel MM, Manz H, Meyerhofer KE, Keller B (2010) Servicelife limitations in vacuum glazing: a transient pressure balance model. Sol Energy Mat Sol Cells 94:1015-1024

20. Caps R, Heinemann U, Ehrmanntraut M, Fricke J (2001) Evacuated insulation panels filled with pyrogenic silica powders - properties and applications. High Temp High Press 33(2): $151-156$

21. Koebel MM, El Hawi N, Lu J, Gattiker F, Neuenschwander J (2011) Anodic bonding of activated tin solder alloys in the liquid state: a novel large-area hermetic glass sealing method. Sol Energy Mat Sol Cells 95:3001-3008

22. Freedonia market study \#2434 (2009) Freedonia group. Cleveland, $\mathrm{OH}$

23. BCC market study \#AVM052B (2009) BCC research Inc. Wellesley, MA

24. Teichner SJ, Nicolaon GA, Vicarini MA, Gardes GEE (1976) Inorganic oxide aerogels. Adv Colloid Interf Science 5:245-273

25. Mehrotra MC (1992) Precursors for aerogels. J Non-Cryst Solids 145:1-10

26. Kistler SS (1932) Coherent expanded aerogels. J Phys Chem 36:52-64

27. Gao GM, Liu DR, Zou HF, Zou LC, Gan SC (2010) Preparation of silica aerogel from oil shale ash by fluidized bed drying. Powder Technol 197(3):283-287

28. Tang Q, Wang T (2005) Preparation of silica aerogel from rice hull ash by supercritical carbon dioxide drying. J Supercritical Fluids 35(1):91-94

29. Li T, Wang T (2008) Preparation of silica aerogel from rice hull ash by drying at atmospheric pressure. Mater Chem Phys 112(2):398-401

30. Shi F, Liu JX, Song K, Wang ZY (2010) Cost-effective synthesis of silica aerogels from fly ash via ambient pressure drying. J Non-Cryst Solids 356(43):2241-2246

31. Baccile N, Babonneau F, Bejoy T, Coradin T (2010) Introducing ecodesign in silica sol-gel materials. J Mater Chem 19: $8537-8559$

32. Rigacci A, Ehrburger-Dolle F, Geissler E et al (2001) Investigation of the multi-scale structure of silica aerogels by SAXS. J Non-Cryst Solids 285:187-193

33. Di Bella G, Arrigo I, Catalfamo P, Corigliano F, Mavilia L (2003) Advances in the extraction of silica from glass cullet. Recycl Reuse Waste Mater Proc Int Symp 63719:137-142

34. Icopini GA, Brantley SL, Heaney PJ (2005) Kinetics of silica oligomerization and nanocolloid formation as a function of $\mathrm{pH}$ and ionic strength. Geochim Cosmochim Acta 69(2):293-303

35. West JK, Hench LL (1995) Molecular-orbital models of silica rings and their vibrational spectra. J. Am. Ceramic Soc 78(4): 1093-1096 
36. Greenberg SA, Sinclair D (1955) The polymerization of silicic acid. J Phys Chem 59(5):435-440

37. Allen LH, Matijevic E (1970) Stability of colloidal silica: II. Ion exchange. Interface Sci 33(3):420-429

38. Grun M, Unger KK, Matsumoto A (1999) Novel pathways for the preparation of mesoporous MCM-41 materials: control of porosity and morphology. Micropor Mesopor Mater 27(2-3): 207-216

39. Gross J, Fricke J, Hrubesh LW (1992) Sound-propagation in SiO2 aerogels. J Acoust Soc Am 91(4):2004-2006

40. Ray SK, Maiti CK, Lahiri SK et al (1992) Properties of silicon dioxide films deposited at low-temperatures by microwave plasma enhanced decomposition of Tetraethylorthosilicate. J Vac Sci Technol, B 10(3):1139-1150

41. Mackenzie JD, Bescher EP (1998) Structures, properties and potential applications of Ormosils. J Sol-Gel Sci Technol 13(1-3):371-377

42. Yano S, Iwata K, Kurita K (1998) Physical properties and structure of organic-inorganic hybrid materials produced by solgel process. Mater Sci Eng C Biomim Supramol Syst 6(2-3):75-90

43. Chen Y, Iroh JO (1999) Synthesis and characterization of polyimide silica hybrid composites. Chem Mater 11(5): 1218-1222

44. Liu RL, Shi YF, Wan Y et al (2006) Triconstituent Co-assembly to ordered mesostructured polymer-silica and carbon-silica nanocomposites and large-pore mesoporous carbons with high surface areas. J Am Chem Soc 128(35):11652-11662

45. Kelts LW, Effinger NJ, Melpolder SM (1986) Sol-gel chemistry studied by $1 \mathrm{H}$ and $29 \mathrm{Si}$ nuclear magnetic resonance, J. Non.Cryst. Solids 83:353-374

46. Bernards TNM, Oomen EWJL, Vanbommel MJ, Boonstra AH (1992) The effect of TEOG on the hydrolysis condensation mechanism of a 2-step sol-gel process of TEOS. J Non-Cryst Solids 142(3):215-224

47. Jada SS (1987) Study of tetraethyl orthosilicate hydrolysis by in situ generation of water. Comm Am Chem Soc 70(11):C298C300

48. Aelion R, Loebel A, Eirich F (1950) Hydrolysis of ethyl silicate. J Am Chem Soc 72(12):5705-5712

49. Belton DJ, Deschaume O, Patwardhan SV, Perry CC (2010) A solution study of silica condensation and speciation with relevance to in vitro investigations of biosilicification. J Phys Chem B 114(31):9947-9955

50. Assink RA, Kay BD (1988) Sol-gel kinetics: I. Functional group kinetics. J Non Cryst Solids 99:359-370

51. Assink RA, Kay BD (1988) Sol-gel kinetics: II. Chemical speciation modeling. J Non Cryst Solids 104:112-122

52. Brinker CJ, Keefer KD, Schaefer DW, Ashley CS (1982) Sol-gel transition in simple silicates. J Non Cryst Solids 48:47-64

53. Gurav JL, Nadargi DY, Rao AV (2008) Effect of mixed catalysts system on TEOS-based silica aerogels dried at ambient pressure. Appl Surf Sci 255(5):3019-3027

54. Jarzebski AB, Lorenc J, Aristov YI, Lisitza N (1995) Porous texture characteristics of a homologous series of base-catalyzed silica aerogels. J Non-Cryst Solids 190(3):198-205

55. Kesmez O, Kiraz N, Burunkaya E, Camurlu HE, Asilturk M, Arpac E (2010) Effect of amine catalysts on preparation of nanometric $\mathrm{SiO} 2$ particles and antireflective films via sol-gel method. J Sol-Gel Sci Technol 56(2):167-176

56. Cao WQ, Hunt AJ (1994) Improving the visible transparency of silica aerogels. J Non-Cryst Solids 176(1):18-25

57. Pajonk GM, Elaloui E, Achard P, Chevalier B, Chevalier JL, Durant M (1995) Physical properties of silica gels and aerogels prepared with new polymeric precursors. J Non-Cryst Solids 186:1-8
58. Begag R (1996) Synthèse et propriétés physico-chimiques de carbogels de silice préparés par la méthode sol-gel (en catalyse acide) à partir de polyéthoxydisiloxanes. $\mathrm{Ph} \mathrm{D}$ thesis Université de Lyon I (France)

59. Schultz JM, Jensen KI, Kristiansen FH (2005) Super insulating aerogel glazing. Solar Mater Solar Cells 89:275-285

60. Brinker CJ, Scherer GW (1990) Sol-gel science: the physics and chemistry of sol-gel processing. Academic Press, New York, NY

61. Einarsrud M-A, Haereid S (1994) Preparation of transparent, monolithic silica xerogels with low density. J Sol-Gel Sci Technol 2(1-3):903-906

62. Aravind PR, Shajesh P, Soraru GD, Warrier KG (2010) Ambient pressure drying: a successful approach for the preparation of silica and silica based mixed oxide aerogels. J Sol-Gel Sci Technol 54:105-117

63. Pajonk GM (1989) Drying methods preserving the textural properties of gels. Rev Phys Appl 24(C4):13-22

64. Bisson A, Rigacci A, Lecomte D, Rodier E, Achard P (2003) Drying of silica gels to obtain aerogels : phenomenology and basic techniques, progress in drying technologies, vol 4,- special issue of Drying Technol 21(4): 593-628

65. Iler RK (1979) The chemistry of silica. Wiley, New York NY

66. Calas S (1997) Surface et porosité dans les aérogels de silice: étude structurale et texturale. $\mathrm{PhD}$ thesis Université de Montpellier (France)

67. Bisson A (2004) Synthèse et étude de matériaux nanostructurés à base de silice pour la superisolatuion thermique. $\mathrm{PhD}$ thesis Mines ParisTech (France)

68. Hrubesh LW, Pekala RW (1994) Thermal properties of organic and inorganic aerogels. J Mater Res 9:731-738

69. Deng Z, Wang J, Wu A, Shen J, Zhou B (1998) High strength $\mathrm{SiO} 2$ aerogel insulation. J Non-Cryst Solids 225:101-104

70. Li L, Yalcin B, Nguyen BN, Meador MA, Cakmak M (2009) Flexible nanofiber-reinforced aerogel (xerogel) synthesis, manufacture and characterization. Appl Mater Interf 1(11): 2491-2501

71. Bisson A, Rigacci A, Lecomte D, Achard P (2004) Effective thermal conductivity of divided silica xerogels beds. J NonCryst Solids 350:379-384

72. Buratti C, Moretti E (2011) Lighting and energetic characteristics of transparent insulating materials : experimental data and calculation. Indoor Build Environ 20(4):400-411

73. Haereid S (1993) Preparation and characterization of transparent monolithic silica xerogels with low density. PhD thesis NTNU (Norway)

74. Schwertfeger F, Frank D, Schmidt M (1998) Hydrophobic waterglass based aerogels without solvent exchange or supercritical drying. J Non-Cryst Solids 225:24-29

75. Rao VA, Bhagat SD, Hirashima H, Pajonk GM (2006) Synthesis of flexible silica aerogels using methyltrimethoxysilane (MTMS) precursor. J Colloid Interf Sci 300:279-285

76. Kartal AM, Erkey C (2010) Surface modification of silica aerogels by hexamethyldisilazane-carbon dioxide mixtures and their phase behavior. J Supercritical Fluids 53:115-120

77. Smith DM, Deshpande R, Brinker CJ (1992) Preparation of lowdensity aerogels at ambient pressure. Mat Res Soc Symp Proc 271:567-572

78. Hwang SW, Kim TY, Hyun SH (2008) Optimization of instantaneous solvent exchange/surface modification process for ambient synthesis of monolithic silica aerogels. J Colloid Interf Sci 322:224-230

79. Reim M, Korner W, Manar J, Korder S, Ardini-Schuster M, Ebert HP, Fricke J (2005) Silica aerogel granulate material for thermal insulation and daylighting. Sol Energy 79(2):131-139

80. Smith DM, Maskara A, Boes U (1998) Aerogel-based thermal insulation. J Non-Cryst Solids 225:254-259 
81. Woignier T, Phalippou J (1989) Scaling law variation of the mechanical properties of silica aerogels. Rev Phys Appl C4: 179-184

82. Ryu J (2000) Flexible aerogel superinsulation and its manufacture. US Pat. \# 6068882

83. Trifu R, Bhobho N (2007) Flexible coherent insulating structures. US2007173157

84. Chandradass J, Kang S, Bae D-S (2008) Synthesis of silica aerogel blanket by ambient drying method using waterglass based precursor and glass wool modified alumina sol. J NonCryst Solids 354:4115-4119

85. Bardy ER, Mollendorf JC, Pendergast DR (2007) Thermal conductivity and compressive strain of aerogel insulation blankets under applied hydrostatic pressure. J Heat Transf 129: 232-235

86. Tang Y, Polli A, Bilgrien CJ, Young DR, Rhine WE, Gould GL (2007) Aerogel-foam composites. WO Pat. \# 2007146945

87. Lee JK (2007) Organic aerogls reinforced with inorganic fillers. US Pat. \# 2007259979

88. Ristic-Lehmann C, Farnworh B, Dutta A, Reis BE (2008) Aerogel/PTFE composite insulating material. US Pat. \# 7349215 B2

89. Mensahi J, Bauer U, Pothmann E, Peterson AA, Wilkins AK, Anton M, Doshi D, Dalzell W (2007) Aerogel based composites. WO Pat. \# 2007047970

90. Mackenzie JD, Chung YJ, Hu Y (1992) Rubbery ormosils and their applications. J Non-Cryst Solids 147\&148:271-279

91. Ou DL, Gould GL (2005) Ormosil aerogels containing silicon bonded linear polymers. WO Pat. \# 2005068361

92. Ou DL, Gould GL, Stepanian CJ (2006) Ormosil aerogels containing silicon bonded polymethacrylate. WO Pat. \# 2005098553

93. Kanamori K, Aizawa M, Nakanishi K, Hanada T (2008) Elastic organic-inorganic hybrid aerogels and xerogels. J Sol-Gel Sci Technol 48:172-181

94. Capadona LA, Meador MA, Alunni A, Fabrizio EF, Vassilaras P, Leventis N (2006) Flexible, low-density polymer cross-linked silica aerogels. Polymer 47:5754-5761

95. Leventis N, Mulik S, Wang X, Dass A, Patil VU, Sotiriou-Leventis C, Lu H, Churu G, Capecelatro A (2008) Polymer nano-encapsulation of template mesoporous silica monoliths with improved mechanical properties. J Non-Cryst Solids 354:632-644

96. Randall JP, Meador MA, Jana SC (2011) Tailoring mechanical properties of aerogels for aerospace. ACS Appl Mater Interf 3:613-626

97. Rhine WE, Ou, DL, Sonn JH (2007) Hybrid organic-inorganic materials and methods of preparing the same, WO Pat. \# 2007126410

98. Leventis N, Palczer A, McCorkle L (2005) Nanoengineered silica-polymer composite aerogels with no need for Supercritical fluid drying. J Sol-Gel Sci Technol 35:99-105

99. Yang H, Kong X, Zhang Y, Wu C, Cao E (2011) Mechanical properties of polymer-modified silica aerogels dried under ambient pressure. J Non-Crystal Solids 357:3447-3453

100. Pekala RW, Kong FM (1992) Resorcinol-formaldehyde aerogels and their carbonised derivatives. Polym Prepr 30:221-223

101. Lu X, Caps R, Fricke J, Alviso CT, Pekala RW (1995) Correlation between structure and thermal conductivity of organic aerogels. J Non-Cryst Solids 188:226-234

102. Pekala RW, Alviso CT, LeMay JD (1990) Organic aerogels: microstructural dependence of mechanical properties in compression. J Non-Cryst Solids 125:67-75

103. Biesmans GL (1999) Polyisocyanate based aerogel. US Pat. \# 5990184

104. Biesmans G, Randall D, Francais E, Perrut M (1998) Polyurethane-based organic aerogels' thermal performance. J Non-Cryst Solids 225:36-40
105. Rigacci A, Maréchal JC, Repoux M, Moreno M, Achard P (2004) Elaboration of aerogels and xerogels of polyurethane for thermal insulation. J Non-Cryst Solids 350:372-378

106. Lee JK, Gould GK, Rhine W (2009) Polyurea based aerogel for high performance thermal insulation material. J Sol-Gel Sci Technol 49:209-220

107. Egger CC, du Fresne C, Schmidt D, Yang J, Schädler V (2008) Design of highly porous melamine-based networks through a bicontinuous microemulsion templating strategy. J Sol-Gel Sci Technol 48:86-94

108. du Fresne C, Schmidt DF, Egger C, Schädler V (2007) Supramolecular templating of organic xerogels. XVth international sol-gel conference, Montpellier, France, Sept 2-7, p 129

109. Lee JK, Gould GL (2007) Polycyclopentadiene based aerogel: a new insulation material. J Sol-Gel Sci Technol 44:29-40

110. Company website: http://www.airglass.se/

111. Company website: http://www.basf.com

112. Company website: http://www.hoechst.com

113. Frisch G, Zimmermann A, Schwertfeger F (1997) Use of aerogels in agriculture. MX Pat. \# 9706411

114. Vukasovich MS (1970) Fluorescent pigment. GB Pat. \# 1191483

115. Company website: http://www.cabot-corp.com/aerogel

116. Company website: http://www.aerogel.com/

117. Company website: http://aerogel.en.gongchang.com/

118. Company website: http://www.em-power.co.kr/

119. Wang X-Y, Harpster G, Hunter J (2007) Nasa TM-report \#214675

120. Henning S (1985) Large-scal production of airglass. In: Fricke J (ed) Aerogels. Springer, Berlin, pp 39-41

121. Pajonk G, Elaloui E, Begag R, Durant M, Chevalier B, Chevalier JL, Achard P (1998) Process for the preparation of monolithic silica aerogels. US Pat. \# 5795557

122. Jensen KI, Kristiansen FH, Schultz JM (2005) Highly insulating and light transmitting aerogel glazing for super-insulating windows : HILI+ (European project ENK6-CT-2002-00648), Public final report

123. Company website: http://www.scobalit.ch/

124. Company website: http://www.birdair.com/

125. Company website: http://www.okalux.de/

126. Company website: http://www.rockwool.com/

127. German product website: http://www.aerowolle.de/

128. Stahl T, Brunner S, Zimmermann M, Ghazi Wakili K, (2011) Thermo-hygric properties of a newly developed aerogel based insulation rendering for both exterior and interior applications. Energy Build 44:114-117

129. Company website: http://www.fixit.ch

130. Company website: http://www.parexlanko.com/

131. Achard P, Rigacci A, Echantillac T, Bellet A, Aulaginer M, Daubresse A. Insulating silica xerogel plaster, International patent WO 2011/083174

132. Ratke L (2008) Herstellung und Eigenschaften eines neuen Leichtbetons: Aerogelbeton. Beton- und Stahlbetonbau 103: 236-243

133. Company website: http://www.roefix.com

134. Company website: http://sto.com/

135. Savolainen K, Pylkkaenen L, Norppa H, Falck G, Lindberg H, Tuomi T, Vippola M, Alenius H, Brouwer D, Mark D, Bard D, Berges M, Jankowska E, Posniak M, Farmer P, Singh R, Krombach F (2008) Vision on safe nanoparticles and nanotechnologies: global and EU perspective. Nanosafety and REACH. Toxicol Lett 180:S21

136. Nel A, Xia T, Mädler L, Li N (2006) Toxic potential of materials at the nanolevel. Science 311:622-627 